\title{
Complutum
}

ISSN: 1131-6993

\section{Evaluando la rentabilidad y productividad de la prospección arqueológica: el Valle del Tajuña (Madrid)}

\author{
José Enrique Benito López ${ }^{1}$
}

Recibido: 18 de marzo de 2019 / Aceptado. 25 de mayo de 2019

Resumen. El presente estudio muestra los resultados de un proyecto de investigación sobre un área unitaria de la Meseta Sur española, el Valle del río Tajuña (Madrid) -216,1 km2-, basado en la prospección arqueológica intensiva de superficie, con cobertura total del terreno y aplicando los métodos de la arqueología territorial con una innovadora metodología, dirigida a optimizar los recursos y resultados que pueda mejorar la gestión del Patrimonio Arqueológico. Siguiendo esta línea de investigación, este trabajo pretende definir unos parámetros imprescindibles y válidos (la rentabilidad y la productividad, entre otros) en cualquier contexto y que permitan la comparación de los resultados de otras prospecciones arqueológicas, con independencia del medio físico y el contexto crono-cultural en que se desarrollen. Para ello se acude a la experiencia acumulada de este proyecto de investigación.

Palabras clave: Meseta sur (Valle del Tajuña, Madrid); Proyecto de prospección arqueológica; Parámetros de análisis; Rentabilidad; Productividad.

\section{[en] The evaluation of effectiveness and productivity on archaeological survey: Tajuña Valley (Madrid)}

\begin{abstract}
The study presents the results of a research project on a specific area of the southern Spanish plateau, the Tajuña Valley (Madrid) -216,1 km2-, based on intensive archaeological survey, with full coverage of the land and applying methods of spatial and territorial archeology with an innovative methodology in order to get to a quality control in this field. So, in this kind of investigation our purpose is define a set of essential standards (effectiveness and productivity) that could be applied in any context, regardless of environmental, chronological and cultural references, in order to compare the results of survey research in archaeology. To that end, we turn to the experience gained in this research project.
\end{abstract}

Keywords: Spanish South Meseta (Tajuña Valley, Madrid); Archaeological survey project; Standards analysis; Effectiveness; Productivity.

Sumario: 1. Introducción. 2. El Proyecto Tajuña y sus resultados. 3. La rentabilidad y la productividad. 4. Conclusiones. 5. Agradecimientos. 6. Bibliografía.

Cómo citar: Benito López, J. E. (2019): Evaluando la rentabilidad y productividad de la prospección arqueológica: el Valle del Tajuña (Madrid). Complutum, 30(1): 79-105.

\section{Introducción.}

La prospección de superficie es un método para localizar, identificar, delimitar e interpretar evidencias arqueológicas ubicadas en el medio físico mediante técnicas no destructivas (Banning 2002, Burillo Mozota 2013: 16,
Mayoral Herrera 2016, Mayoral Herrera et al. 2017).

En un principio, y a diferencia de la excavación, era una actividad carente de método $\mathrm{y}$, salvo algunas excepciones, más propia de aficionados que de arqueólogos profesionales, centrados en la excavación de los yacimientos

\footnotetext{
Área de Protección de la Dirección General de Patrimonio Cultural. Comunidad de Madrid. jose.enrique.benito@madrid.org
} 
arqueológicos. Así, serán las Cartas Arqueológicas iniciadas en los años 1940 las primeras plasmaciones del resultado de las prospecciones arqueológicas en España, siendo pionera la de Soria por Blas Taracena (1941), investigador que había realizado campañas de localización de yacimientos en décadas anteriores, en los que realizaba excavaciones de diferente amplitud para ratificar su cronología (Taracena 1926). La prospección de superficie como actividad habitual en la arqueología tradicional estaba subordinada a la excavación y carecía de un marco teórico específico para desarrollar todas sus posibilidades. En los años sesenta del siglo pasado surgió la ruptura en el enfoque de la prospección arqueológica, dentro del marco de la Nueva Arqueología -New Archaeology- (Binford 1964), con un gran desarrollo en los setenta y ochenta del siglo XX en la tradición norteamericana (King 1978, Dysson 1982) y británica (Haselgrove et al. 1985, Keller y Rupp 1983, Schoffield 1991), y algo más tardíamente en la escandinava, francesa y española (Ruiz Zapatero y Burillo Mozota, 1988: 47). En este momento será cuando la prospección alcance una metodología propia vinculada, en la investigación, al desarrollo de la Arqueología Espacial surgida en la Universidad de Cambridge (Hodder y Orton 1976, Clarke 1977) como un fructífero trasvase de la Geografía Locacional (Hagget 1976) y de la Geomorfología Histórica (Vita-Finzi 1969) (Burillo Mozota 2013: 16). En la actualidad, la prospección de superficie ha adquirido un momento de madurez gracias a la publicación de los primeros grandes proyectos, la introducción de innovaciones tecnológicas como el GPS, la utilización de herramientas de gestión como el SIG y la aplicación de nuevos enfoques teórico-metodológicos derivados del desarrollo de la nueva Arqueología del Paisaje, todo ello queda reflejado en la aparición de numerosas publicaciones, los primeros manuales
(Banning 2002, Collins y Molyneaux 2003, White y King 2007), guías de prospección -muy numerosas en EE.UU. Australia y Reino Unido- (Burke et al. 2017, Connolly 2015, Ifa 2008) y multitud de congresos especializados (Ruiz Zapatero 2004).

Por tanto, en estos últimos años existe un desarrollo y una mejora de las investigaciones basadas en la prospección arqueológica de superficie e importantes intentos por diseñar esquemas de trabajo para proyectos de Arqueología Territorial (Benito-López 1991; San Miguel Maté 1992; Jimeno et al. 1993; VV.AA 1997; VV.AA 2004; García Sanjuán 2005: 63-103; Orejas Saco del Valle 2006; Burillo 2013: 15-38; Moreno Escobar y García Sanjuán 2013; Moreno Escobar 2016, Mayoral Herrera 2016, Mayoral Herrera et al. 2017). Buen ejemplo de ello son los trabajos y proyectos realizados durante estos últimos años por los diversos territorios de la geografía española (destacando entre muchos otros: Chapa et al. 2003 y 2004; Gutiérrez et al. 2007; Domínguez Macarro y García Fernández 2007; García Sanjuán et al. 2011; Moreno Escobar 2011 y 2016 -Andalucía-; Gerrad y Gutiérrez 2012 -Aragón-; Mayoral Herrera et al. 2009 -Extremadura-; Díez Martín 2009 y 2010; García Sánchez 2013 -Castilla y León; Criado Boado et al. 2009 y 2011 -Galicia-; Mayoral Herrera 2016, Mayoral Herrera et al. 2017; etc.). Todo ello es consecuencia tanto de la creciente importancia de la Arqueología del Territorio como de la necesidad cada vez mayor de la gestión del Patrimonio Arqueológico.

Teniendo en cuenta ese interés de la prospección arqueológica de superficie hay que plantearse desde un punto de vista sistemático cuales son las técnicas y decisiones que deben tomarse para plantear correctamente una prospección, pues resulta evidente que según las diferentes estrategias adoptadas serán distintos los resultados. 


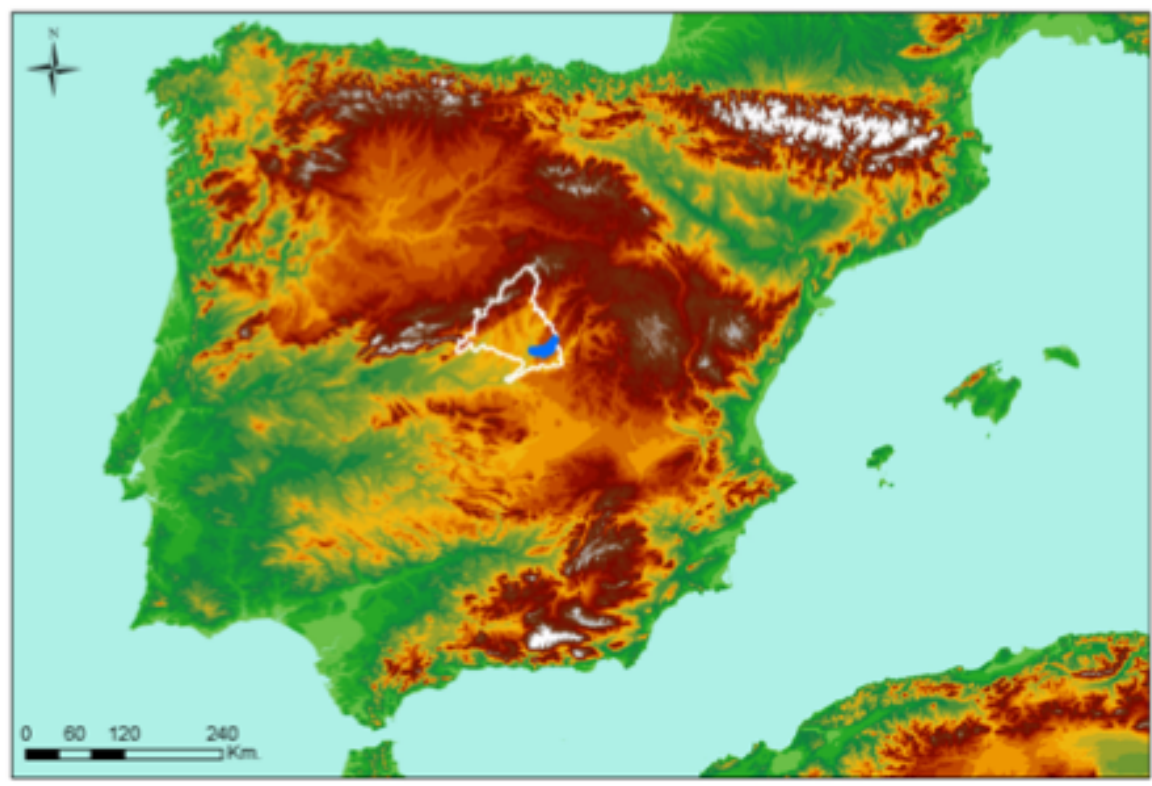

Fig. 1: El marco geográfico del Valle del Tajuña, en la Comunidad de Madrid y en la Península Ibérica.

De este modo, siguiendo la línea teórica elaborada tanto por la Arqueología Anglosajona -norteamericana y británica- como por la Europea -escandinava, francesa, italiana, española...- (Ruiz Zapatero 2004; García Sanjuán 2005; Burillo Mozota 2013), en este estudio se expone una aproximación a la metodología más adecuada para las prospecciones arqueológicas de superficie y se definen aquellos factores que son necesarios y válidos en cualquier contexto y que pueden permitir no sólo la evaluación, sino también la comparación de los resultados de trabajos de prospección arqueológica diferentes (la rentabilidad y la productividad, entre otros), con independencia del medio físico y el marco crono-cultural en el que se desarrollen (Fig. 20). Para ello se acude a la experiencia acumulada en un proyecto de investigación que ha utilizado la prospección sistemática de cobertura total como método de trabajo, en un área unitaria de la Meseta Sur española, el valle del río Tajuña -216,1 km2(Madrid) (Almagro-Gorbea y Benito-López 1993a) (Fig. 1). Aunque esta investigación se desarrolló en los años 90 del siglo XX, la misma ha sido retomada a finales del primer decenio del siglo XXI. Asumo que el enfoque ha quedado superado, ya que el mismo es fruto de su tiempo y responde a lo que se exigía en ese momento en los proyectos de arqueología territorial. Sin embargo, es de gran interés presentar los parámetros de rentabilidad, productividad y control de calidad obtenidos en este proyecto para que los investigadores dispongan de indicadores que permitan la comparación de resultados en prospecciones arqueológicas y puedan abordar nuevos estudios de comparación con las técnicas desarrolladas en los últimos 15/20 años (SIG ...).

\section{EI Proyecto Tajuña y sus resultados.}

El presente estudio es resultado de los trabajos de investigación realizados en el Proyecto Tajuña ${ }^{1}$ que hemos desarrollado durante seis años (1986, 1989-1993), gracias al acuerdo de colaboración entre el Departamento de Prehistoria de la Universidad Complutense de Madrid y la Dirección General de Patrimonio Cultural de la Comunidad de Madrid². El análisis se ha desarrollado en tres niveles: teórico-metodológico, arqueológico y de valoración del patrimonio de la región, resaltando en especial el control, tanto económico como de calidad y puesta en práctica de la prospección de superficie. 


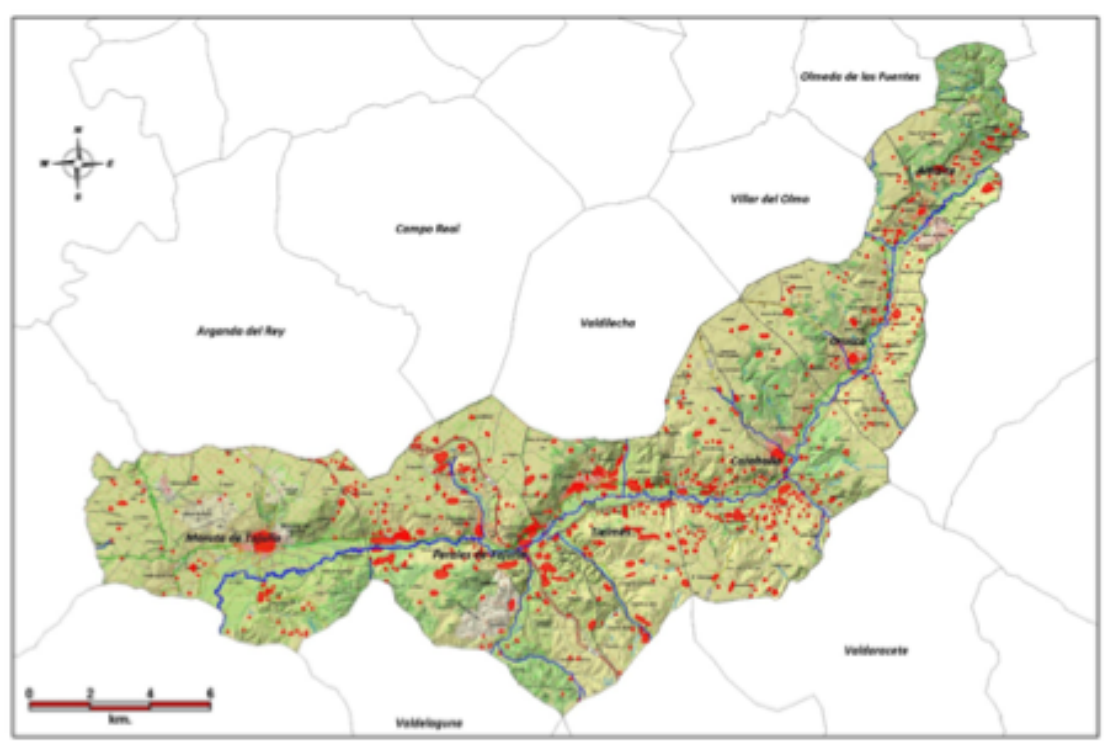

Fig. 2: Mapa topográfico del Valle del Tajuña madrileño con su situación, extensión, límites y emplazamiento de los sitios arqueológicos, tomado del 1:50.000.

Se muestran los resultados alcanzados en el estudio territorial de un área unitaria de la Meseta Sur española como es el Valle del Tajuña en su recorrido por la Comunidad de Madrid (Figs. 1 y 2). Se ha basado en una innovadora metodología (Fig. 3) y obtenido interesantes resultados práctico-arqueológicos, confirmando la hipótesis de trabajo de que tanto desde el punto de vista científico como para la debida valoración cultural es imprescindible realizar el trabajo sistemáticamente y en áreas unitarias. De este modo, la clave principal reside en el establecimiento de un método teórico y su explicitación para la prospección arqueológica de superficie. Por tanto, este tipo de estudios exige una intensidad mínima y que se lleven a cabo en un lapso de tiempo lo más breve posible para ser rentables (Figs. 17, 18, 19, y 20), pues sólo la imprescindible visión de conjunto permite la correcta comprensión y valoración técnica, científica y cultural de los yacimientos y hallazgos aislados.

Una prospección puede considerarse válida si se sustenta sobre una metodología científica conocida que permita evidenciar su grado de fiabilidad y de eficacia. Para conseguir ésta no es suficiente una buena metodología de campo, aunque se adecue a buenos principios teóricos. Su fiabilidad se mide por la precisión alcanzada del conocimiento arqueológico del territorio investigado, lo que requiere una metodología de trabajo que en esta experiencia se ha querido desarrollar. En caso contrario, al desconocer la validez de los resultados, las labores de prospección e inventario/catálogo se convierten en simples usos administrativos ${ }^{3}$. 


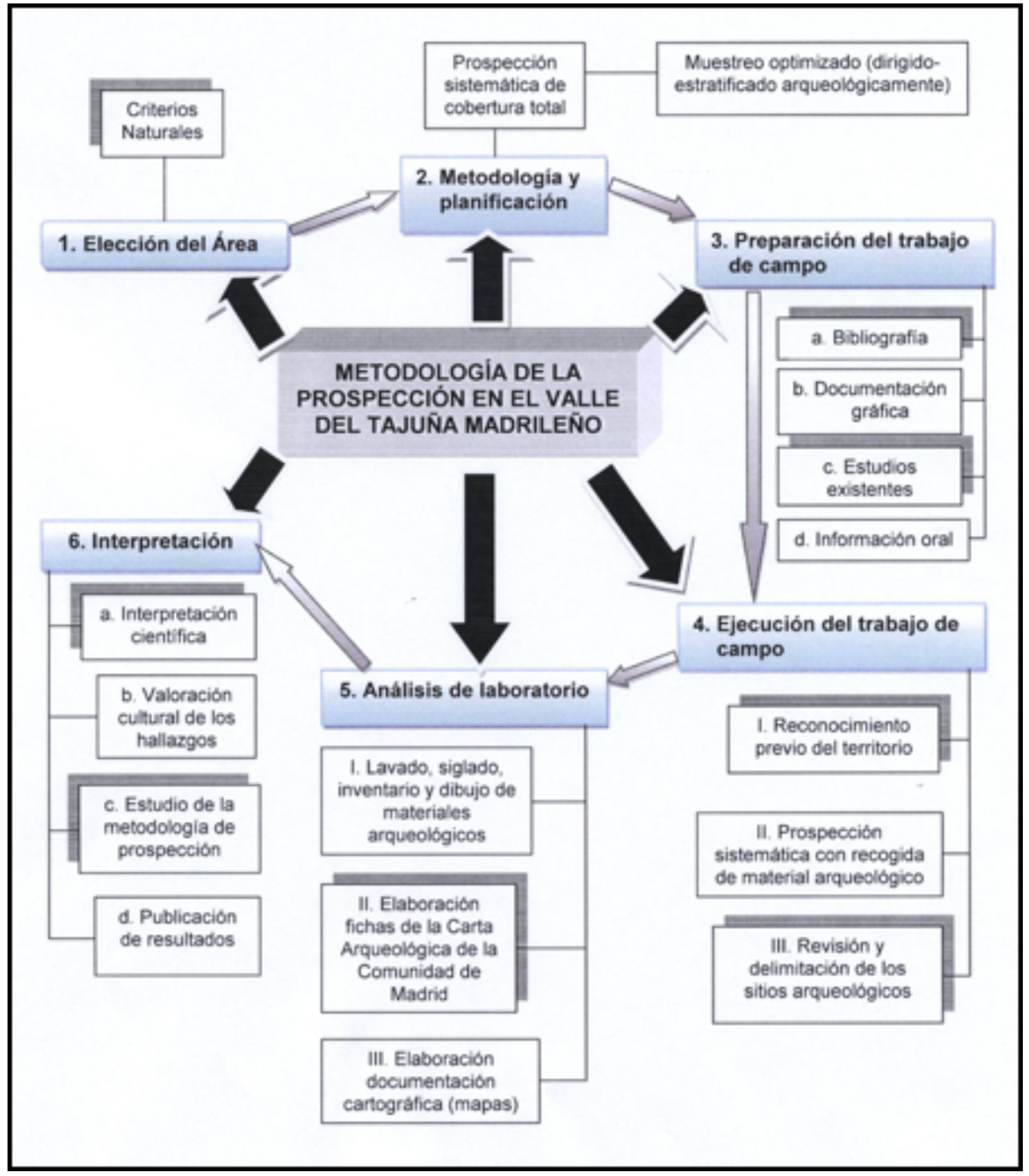

Fig. 3: Esquema de la metodología de la prospección arqueológica en el Valle del Tajuña madrileño. 
Las investigaciones dedicadas a la prospección arqueológica de superficie han supuesto en los últimos años un importante desarrollo y mejora en el diseño de un esquema de trabajo para los proyectos de Arqueología Territorial (Chapa Brunet et al. 2003 y 2004; Ruiz Zapatero 2004; VV.AA. 2004; García Sanjuán 2005; Gutiérrez et al. 2007; Domínguez Macarro y García Fernández 2007; Mayoral Herrera et al. 2009; Gerrard y Gutiérrez 2012; García Sánchez 2013; García Sanjuán et al. 2011: 3716-3737; Moreno Escobar 2013 y 2016, Mayoral Herrera 2016, Mayoral Herrera et al. 2017 ...), si bien buena parte de los estudios carecen de un verdadero capítulo que recoja el planteamiento de la prospección, la explicitación del método y la realización de un análisis de su desarrollo. En este sentido, nuestro objetivo ha sido precisamente llamar la atención sobre esta carencia, presentando una alternativa de planteamientos, desarrollo y explicitación del método de prospección que hagan posible que la prospección arqueológica tenga su justo valor tanto en la investigación como en las labores administrativas.

Por este motivo hemos desarrollado el modelo teórico de la prospección arqueológica de superficie en nuestra zona de estudio, aplicado de forma práctica (Fig. 4). Se ha establecido el armazón conceptual y metodológico del Proyecto Tajuña explicitando una metodología de campo que ha aunado rigor y flexibilidad, ante las circunstancias y características de la zona a prospectar. La investigación ha pretendido la definición de una serie de parámetros de análisis de prospección, imprescindibles y válidos en cualquier contexto y que permitan no sólo la evaluación, sino también la comparación de los resultados de trabajos de prospección arqueológica diferentes, con independencia del medio físico y el marco crono-cultural en el que se desarrollen. Estos parámetros son los siguientes (Benito-López 2016: 126-258):

1. la unidad de prospección,

2. los prospectores y la experiencia,

3. la intensidad de la prospección,

4. el factor tiempo,

5. la circunstancia de los hallazgos,

6. los hallazgos arqueológicos,

7. los factores no controlables por el arqueólogo,

8. los resultados obtenidos en las distintas unidades topográfico/ecológicas,

9. la rentabilidad y la productividad,

10.el control de calidad de resultados en la prospección arqueológica,

11.y las relaciones entre el poblamiento y el medio y el patrón de asentamiento (Benito-López 2016: 259-370).

También se ha querido llamar la atención sobre una cuestión en la que normalmente estas reflexiones coinciden: las dificultades para evaluar correctamente la validez de los trabajos. La secuencial cultural del interior de la Meseta Sur en ese momento no era bien conocida, ya que no existían estratigrafías ni trabajos de seriación actualizados (inicios de los años 90 del siglo XX). Para ello se ha acudido a la experiencia acumulada de este proyecto de investigación, que ha utilizado la prospección sistemática de cobertura total como método de prospección en el valle del río Tajuña (Madrid) -216,1 kms2- (Fig. 1 y 2).

La elección del Valle del Tajuña como unidad territorial para esta investigación se llevó a cabo tras analizar otras diversas alternativas, seleccionándose por diversos motivos tanto medioambientales como de protección, además de los de investigación y formación (Benito-López 2016: 22-23). 


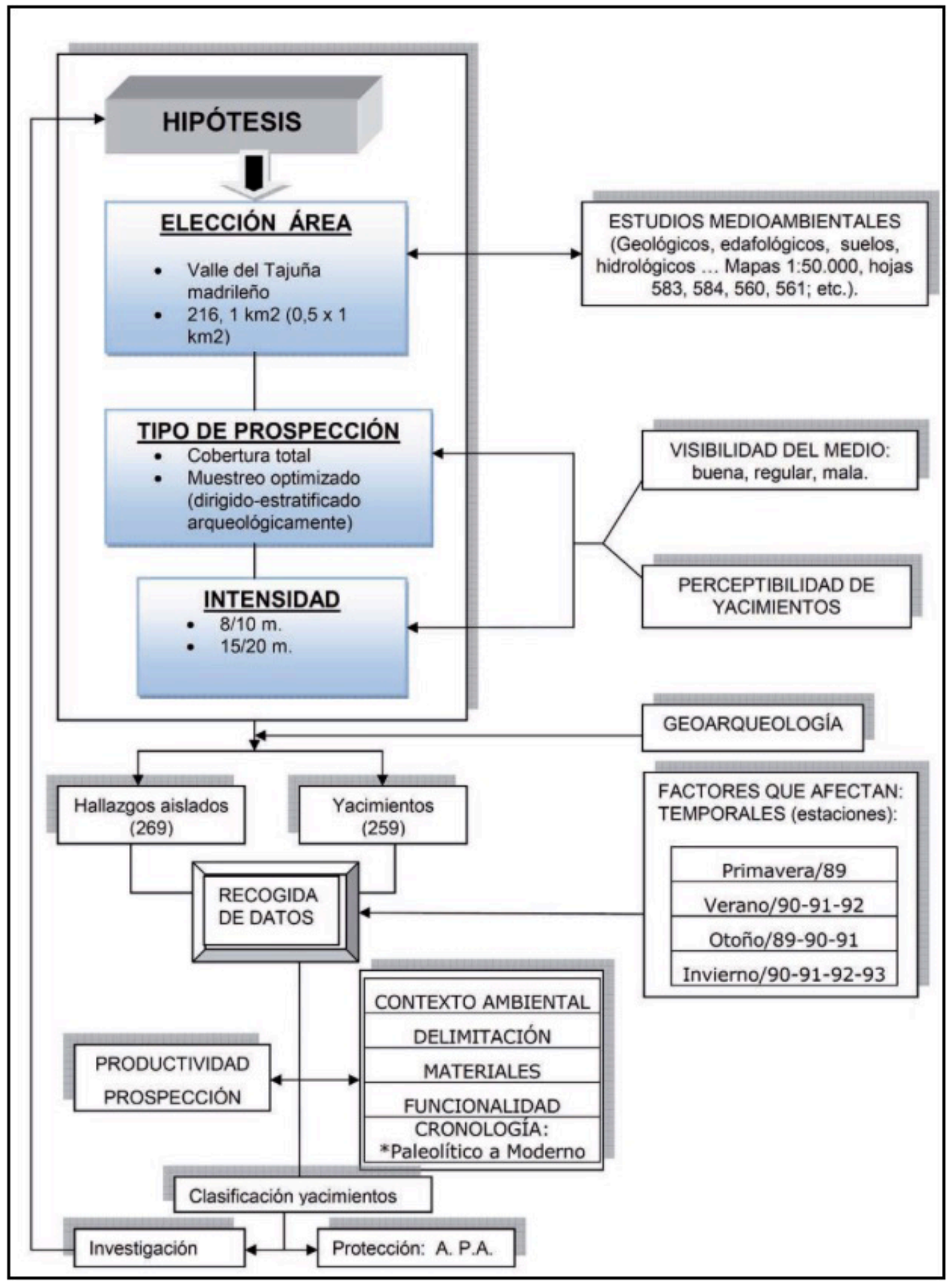

Fig. 4: Diseño de la planificación de la prospección de superficie del Valle del Tajuña madrileño (tomado y modificado de Ruiz Zapatero y Burillo Mozota, 1988: 49). 
De este modo, los aspectos de investigación científica y docencia quedaban complementados con los de protección y valoración del Patrimonio Arqueológico y Cultural, de acuerdo con las actuales tendencias de la Arqueología y con el deseo expreso del Departamento de Prehistoria de la Universidad Complutense para colaborar en el estudio y puesta en valor del Patrimonio Arqueológico de la Comunidad de Madrid.

Desde el punto de vista del marco geográfico (Fig. 2), si se pone en relación el medio físico y económico con el patrón de asentamiento prehistórico e histórico (yacimientos arqueológicos) de la zona, se ha comprobado que los yacimientos arqueológicos están distribuidos por todo el territorio del Valle del Tajuña madrileño, pero destaca su mayor concentración en las zonas de ladera que se corresponden con las curvas de nivel de 600-700 m. (Fig. 2), lo que a su vez coincide con las zonas de baja productividad agrícola y, en el mapa de cultivos y aprovechamientos, con la zona de terrenos productivos no labrados, además de secano e improductivo. Geológicamente, en estas zonas de laderas se ubican los suelos terciarios con alguna intrusión de algunos suelos cuaternarios (Benito-López 2016: Figs. I.3, I.4, I.11 y I.12). Por lo cual, como consideración concluyente se puede decir que las poblaciones prehistóricas e históricas del Valle del Tajuña madrileño se asentaban en las zonas de baja productividad económica (agrícola y ganadera), pero en zonas estratégicas (resguardados de los vientos del Norte a la solana, fuera de llanuras de inundación, y con control del territorio), para tanto un buen control territorial como un mejor aprovechamiento económico, siempre dependiendo de las posibilidades naturales y tecnológicas.

La distribución geográfica de los sitios arqueológicos según las diversas áreas topográfico-ecológicas ha ofrecido un interés especial que cabe diferenciar en sentido transversal a lo largo del Valle del río Tajuña en su tramo madrileño, pues reflejan claras preferencias culturales en la elección de los asentamientos.

De tal manera, casi el $50 \%$ del territorio prospectado pertenece al páramo $(46,46 \%)$, el $34,70 \%$ a la ladera y solamente el $9,69 \%$ a la vega (Benito-López 2016: Figs. III.65 y III.65.1). En relación a estos datos hay una clara tendencia a la concentración de los asentamientos en la zona de ladera $-62,98 \%$ de los hallazgos- y también hay una relativa concen- tración en la vega $-13,83 \%$ de los sitios- si se tiene en cuenta que el territorio que le corresponde es muy reducido, comparado con las otras dos unidades. Frente a esto está el páramo con el $23,19 \%$ de los hallazgos y donde más que relativa concentración se podría hablar de dispersión de sitios, puesto que su extensión sobre el Valle del Tajuña es casi la mitad de este y en muchos casos -más del doble de los sitios- son hallazgos aislados (15,96\%) (Fig. 6) (Benito-López 2016: Figs. III.65 y III.65.2).

Del mismo modo, un aspecto importante en el Proyecto Tajuña ha sido la rentabilidad de la prospección arqueológica que ha quedado justificada por los resultados arqueológicos obtenidos. En nuestra investigación hemos establecido unas medias de rentabilidad económica y arqueológica partiendo de los estudios realizados en la zona prospectada (Figs. 6, 7, $8,9$ y 10$)$.

Una vez inspeccionado el territorio y habiendo realizado un estudio analítico, nos ha permitido considerar cómo prospectar las zonas óptimas, en torno al $40 \%$ del territorio, que contienen alrededor del $70 \%$ de los sitios arqueológicos con un grado de confianza en torno al 80\% (Figs. 6, 7 y 8) (Benito-López 2016: Figs. III.72, III.73 y III.73.1). Estas zonas óptimas, se sitúan en las áreas de ladera principalmente, y en el límite de esta con las otras unidades topográfico-ecológicas (vega y páramo), además de territorios por donde discurren cursos de agua o existen manantiales.

De esta manera, estudiando el mapa de dispersión de sitios de los distintos municipios del Valle, se observa que las cuadrículas totalmente prospectadas demuestran cómo los hallazgos se concentran en una banda geográfica correspondiente a la Vega del Tajuña con sus laderas y afluentes (Fig. 2) (Benito-López 2016: Figs. I.3 y I.16).

También es necesario contar con un sistema objetivo de control de calidad de los resultados. En el Proyecto Tajuña se muestra una innovadora metodología específicamente dirigida a ofrecer un control de calidad que permita valorar objetivamente los resultados de una prospección. Este sistema es imprescindible para su ulterior utilización en investigaciones científicas, en la gestión del Patrimonio Arqueológico e, incluso, para evaluar la relación calidad/costes desde un estricto punto de vista económico. En este sentido, el porcentaje de coincidencia, tanto de relocalización como de los sitios no localizados en la prospección 
o en el control, es el índice de calidad de la prospección. A su vez, como rentabilidad se ha considerado la relación esfuerzo/rendimiento, que se puede medir en horas/sitio, horas $/ \mathrm{km} 2$, $€($ ptas. $) / \mathrm{km} 2$ o $€($ ptas. $) /$ sitio.

El método consiste en volver a prospectar una pequeña parte del territorio elegido -entre 0,2 y $8 \%$ del territorio total según su extensiónen lo que se llama Prospección de Control, con unos requisitos mínimos: 1) sobre un área elegida por un muestro ciego pero dirigido, 2) realizado por un equipo que no haya participado ni conozca los resultados obtenidos en el proyecto, y 3) que dicho equipo sí tenga experiencia en este tipo de prospección. La comparación de resultados entre la prospección original y la de control es lo que permite evaluar su calidad. Este sistema de control de calidad de la prospección es poco costoso en tiempo y medios y permite conocer la fiabilidad de los resultados obtenidos, Además, también se ha evidenciado que es posible, a través de un sistema objetivo de muestreo, llegar a conocer la calidad de una determinada prospección por medio de una metodología adecuada.

El sistema de control utilizado es fácil y poco costoso. Se ha evidenciado operativo y eficaz como medio para dar fiabilidad y valor científico a los resultados, tanto desde el punto de vista arqueológico como de la gestión del Patrimonio. En consecuencia, sin este control de calidad, los resultados de una prospección carecen de validez objetiva.

Este interés por el control y la optimización de los resultados puede considerarse una novedad metodológica, no sólo en España, y de particular importancia en el futuro en el campo de la Administración y de la investigación científica.

La referida fiabilidad se puede medir por la precisión lograda en el conocimiento arqueológico del territorio estudiado, lo que exige una metodología de trabajo como la desarrollada en esta experiencia. Para ello se ha experimentado como eficaz el método de comparar, en $\mathrm{n}^{\mathrm{o}} \mathrm{y}$ porcentaje, los sitios (yacimientos y hallazgos aislados) localizados en la prospección con los hallados en la Prospección de Control por medio de una muestra ciega dirigida y con el conjunto de yacimientos conocidos, así como el análisis de la densidad de yacimientos que permite comparar las densidades potenciales con las realmente obtenidas (Benito-López 2016: Figs. III.83, III.83.1, III.84, III.85 y III.87).
En todo trabajo de prospección se debería exigir un control de calidad. Ello es importante ante el riesgo de destrucción de una zona, ya que si ésta está mal prospectada, es evidente el peligro que pueden correr los yacimientos desconocidos en ella existentes, por lo que conocer la calidad de una prospección es tarea previa para todo tipo de planificación territorial eficaz. Este hecho se debe tener particularmente en cuenta a la hora de establecer las posibles áreas de protección arqueológica (APA) para conservar o prevenir la destrucción de yacimientos de posibles deterioros.

La principal aplicación de esta innovación metodológica puede estar en casos de prospecciones territoriales de urgencia que afecten a amplias áreas imposibles de prospectar exhaustivamente, esto es, por cobertura total, así como en casos, relativamente frecuentes, en los que la limitación de medios aconseje optimizar los recursos, lo que exige una prospección dirigida.

Del mismo modo, es evidente la trascendencia económica del control de calidad, ya que, como ocurre siempre que se actúa en campos donde tiene repercusión el costo, lógicamente la rentabilidad de la inversión realizada está en proporción directa con la calidad de los resultados obtenidos. Esta preocupación por el control de los resultados y la optimización de los recursos debe considerarse, no sólo una novedad metodológica, sino, sobre todo, un procedimiento insoslayable por su importancia en el campo de la Administración y de la investigación científica. También se debe tener presente que esta forma es la única correcta para abordar una tarea de prospección, lo que supone implicaciones deontológicas, por ser normas de actuación obligadas en este tipo de actividad arqueológica que se deben respetar si se desea que el trabajo realizado sea un buen trabajo profesional (Almagro-Gorbea, Benito-López y Martín Bravo 1996).

En este trabajo se ha presentado la secuencia cultural del Valle del Tajuña madrileño a partir de los resultados obtenidos en la prospección arqueológica de cobertura total. De este modo, se ha mostrado un sugerente análisis de la secuencia cultural de los asentamientos localizados (Fig. 2) -528 sitios arqueológicos desde el paleolítico a nuestros días- en relación con el medio que los circunda (Benito-López 2016: Figs. IV.1 a IV.3.2). Del examen de los datos (Benito-López 2016: Figs. IV.1 y IV.1.1) se aprecia el claro predominio 
del aprovechamiento de las laderas como punto de ubicación del hábitat, entendiendo por tales la zona de transición entre el área de vega, que es por donde discurre el río y sus afluentes, y el páramo, que son las zonas altas y en gran medida llanas.

Los resultados de esta prospección intensiva permiten delinear las tendencias generales de la evolución del hábitat en esta zona tan peculiar de la Meseta, como son los valles excavados en sus páramos, al menos a partir de la Prehistoria reciente, etapas sobre las que se ha obtenido suficiente información ${ }^{4}$. El panorama que ofrece el proceso de evolución del hábitat en esta zona intermedia del Valle del Tajuña ha debido de comenzar a definirse ya a partir del Calcolítico, debido a un proceso que pudiera considerarse de colonización agrícola. Este proceso, con lógicas fluctuaciones, tal vez más cualitativas que cuantitativas, parece caracterizarse por ser cada vez más intenso, prolongándose prácticamente hasta nuestros días, lo que supone un marcado carácter conservador, como consecuencia de una lenta pero progresiva adaptación a un medio ambiente muy concreto caracterizado por su situación entre vega y páramo que predetermina en gran medida las posibilidades de explotación y de hábitat. Por último, interesa destacar el hecho de que los resultados son bastante homogéneos en las tres unidades (vega, ladera y páramo) de tal manera que los valores altos y medios corresponden a hallazgos de estas cronologías en las tres unidades (Benito-López 2016: Figs. IV.3 y IV.3.1).

El esquema del poblamiento que se obtiene de la distribución cronológico-cultural dentro de las unidades geográficas en el Valle del Tajuña, independientemente de que en algún caso pueda atender a caracteres de diverso tipo (defensivo, etc.), creemos que atiende a una relación eminentemente medio-ambiental entre los grupos humanos y el territorio. Por todo lo cual, los sitios se sitúan en los lugares óptimos del territorio para el control de este y su aprovechamiento, y estos lugares son principalmente las zonas de laderas y sus bordes tanto por la parte de vega como por la zona del páramo (Benito-López 2016: Figs. IV.3 y IV.3.1).

El patrón de asentamiento de éste ámbito madrileño, con una clasificación cronológico-cultural de los yacimientos arqueológicos localizados, ha permitido establecer una pri- mera aproximación a la secuencia del Valle del Tajuña (Benito-López 2016: Figs. IV.5, IV.6, IV.7, IV.8, IV.9, IV.10 y IV.11). Así, la prospección sistemática de superficie ha proporcionado un total de 528 sitios arqueológicos (Fig. 2). De éstos sólo 259, el 49,05\%, pueden considerarse yacimientos y el resto, 269, el 50,95\%, son hallazgos aislados o inciertos (Fig. 17). Estos datos suponen una productivi$\operatorname{dad}^{5}$ media de 2,78 sitios $/ \mathrm{km} 2$, de los que 1,36 son yacimientos y 1,42, hallazgos aislados (Figs. 9, 10 y 17). El conjunto de estos datos ofrece ya una aproximación inicial a la densidad de yacimientos característica de esta zona de la Meseta, independientemente de su distribución espacial y cronológica. Es evidente la escasa variación de unos términos a otros, lo que refleja la validez de los resultados e, indirectamente, la metodología de prospección empleada.

\section{La productividad y la rentabilidad.}

Toda prospección arqueológica, independientemente del sistema utilizado -cobertura total, muestreo probabilístico, etc.-, tiene una serie de gastos económicos (materiales y humanos) y la rentabilidad de ésta se justifica por los resultados arqueológicos obtenidos, en buena medida lo que se denomina efectividad de la prospección (Miller 1989) y más recientemente quality assurance de la prospección (Banning et al. 2017).

De este modo, en nuestra investigación hemos establecido unas medias de rentabilidad económica y arqueológica, partiendo de los estudios realizados en la zona prospectada del Valle del Tajuña madrileño: términos municipales de Morata de Tajuña, Perales de Tajuña, Tielmes, Carabaña, Orusco de Tajuña y Ambite (Figs. 1 y 2 ).

La Comunidad de Madrid, para la realización de La Carta Arqueológica, estableció unos baremos medios de prospección en torno a las 27.000 ptas. $/ \mathrm{km} 2$-años 90 del siglo XX(Velasco 1991: 262) -en la actualidad equivale a 162,27€-. Así, en base a estos datos económicos para todo el Valle del Tajuña y haciendo una prospección sistemática de cobertura total, previa petición de los permisos correspondientes a cada municipio, se obtuvieron los siguientes presupuestos (Fig. 5): 


\begin{tabular}{|c|c|c|c|c|}
\hline \multicolumn{5}{|c|}{ SUPERFICIE Y PRESUPUESTO EN EL VALLE DEL TAJUÑA MADRILEÑO } \\
\hline Municipio & $\begin{array}{c}\begin{array}{c}\text { Superficie } \\
(\mathrm{km} 2 / 100 \%)\end{array} \\
\end{array}$ & $\begin{array}{c}\text { Presupuesto } \\
(\text { Ptas. }-€ / 100 \%)\end{array}$ & $\begin{array}{l}\text { Superficie } \\
(\mathrm{km} 2 / 40 \%)\end{array}$ & $\begin{array}{c}\text { Presupuesto } \\
\text { (Ptas. } € / 40 \%)\end{array}$ \\
\hline Morata de Tajuña & 45,2 & $\begin{array}{c}1.000 .000 \text { ptas. } \\
6.010,12 €\end{array}$ & 18,08 & $\begin{array}{c}\text { 400.000ptas. } \\
2.404,05 €\end{array}$ \\
\hline Perales de Tajuña & 48,9 & $\begin{array}{c}1.500 .000 \text { ptas. } \\
9.015,18 €\end{array}$ & 19,56 & $\begin{array}{c}\text { 600.000ptas. } \\
3.606,07 €\end{array}$ \\
\hline Tielmes & 26,9 & $\begin{array}{c}551.282 \mathrm{ptas} \\
3.313,27 € . \\
\end{array}$ & 10,76 & $\begin{array}{c}\text { 202.513ptas. } \\
1.325,31 €\end{array}$ \\
\hline Carabaña & 47,6 & $\begin{array}{c}975.503 \text { ptas. } \\
5.862,89 €\end{array}$ & 19,04 & $\begin{array}{c}\text { 390.201ptas. } \\
2.345,28 €\end{array}$ \\
\hline Orusco de Tajuña & 21,5 & $\begin{array}{c}\text { 516.000ptas. } \\
3.101,22 €\end{array}$ & 8,60 & $\begin{array}{c}\text { 206.400ptas. } \\
1.240,49 €\end{array}$ \\
\hline Ambite & 26,0 & $\begin{array}{c}\text { 624.000ptas. } \\
3.750,32 €\end{array}$ & 10,40 & $\begin{array}{c}249.600 \text { ptas. } \\
1.500,13 €\end{array}$ \\
\hline TOTAL & 216,1 & $\begin{array}{c}\text { 5.166.785ptas. } \\
31.053 €\end{array}$ & 86,44 & $\begin{array}{c}2.066 .714 p t a s . \\
12.421,20 €\end{array}$ \\
\hline
\end{tabular}

Fig. 5: Superficie y presupuesto en el Valle del Tajuña madrileño (rentabilidad económica).

Una vez prospectado el territorio del Tajuña y habiendo realizado un estudio analítico, consideramos que inspeccionando las zonas optimas, en torno al $40 \%$ del territorio, se pueden localizar alrededor del $70 \%$ de los sitios arqueológicos con un grado de confianza en torno al 80\% (Figs. 6, 7 y 8). Estas zonas optimas, se sitúan en las áreas de ladera princi- palmente, y en el límite de esta con las otras unidades topográfico-ecológicas (vega y páramo), además de territorios por donde discurren cursos de agua o existen manantiales. Esto queda confirmado en los resultados obtenidos en los distintos municipios del Valle del Tajuña, prospectados sistemáticamente y mediante Cobertura Total (Fig. 6):

\begin{tabular}{|c|c|c|c|}
\hline \multicolumn{4}{|c|}{ RENTABILIDAD ARQUEOLÓGICA EN EL VALLE DEL TAJUNA MADRILEÑO } \\
\hline $\begin{array}{c}\text { Unidades topográfi- } \\
\text { co-ecológicas }\end{array}$ & \% Unidad & $\begin{array}{c}\text { Rentabilidad \% sitios } \\
\text { arqueológicos }\end{array}$ & $\begin{array}{c}\text { Rentabilidad N } \\
\text { arqueoliógicos } \\
\text { arques }\end{array}$ \\
\hline Vega & 9,69 & 13,83 & 65 \\
\hline Ladera & 34,70 & 62,98 & 296 \\
\hline Páramo & 46,46 & 23,19 & 109 \\
\hline TOTAL & & & $\mathbf{4 7 0}$ \\
\hline
\end{tabular}

Fig. $6^{6}$ : Rentabilidad arqueológica en el Valle del Tajuña madrileño.

De esta manera, esta estrategia podría ahorrar y rentabilizar el tiempo, el personal y los medios económicos, al tener que inspeccionar solamente algo más de un tercio del territorio. Así, estableciendo una prospección a las zonas optimas de los diferentes municipios con un muestreo optimizado (dirigido-estratificado arqueológicamente) se obtienen unos resultados más satisfactorios, a nivel económico y de tiempo empleado (Figs. 5 y 6 ) además de conseguir más del $70 \%$ de los resultados arqueológicos (Figs. 7 y 8): 


\begin{tabular}{|c|c|c|}
\hline \multicolumn{3}{|c|}{ PRODUCTIVIDAD ARQUEOLÓGICA EN MUESTREO OPTIMIZADO ARQUEOLÓGICO } \\
DEL VALLE DEL TAJUÑA MADRILEÑO
\end{tabular}

\begin{tabular}{|c|c|c|}
\hline Tielmes & 42,74 & 62,50 \\
\hline Carabaña & 47,58 & 82,58 \\
\hline Orusco de Tajuña & 40,23 & 68,08 \\
\hline Ambite & 51,19 & 85,93 \\
\hline & & \\
\hline & $\mathbf{4 4 , 3 5}$ & $\mathbf{7 3 , 2 0}$ \\
\hline
\end{tabular}

Fig. 7: Productividad arqueológica en muestreo optimizado (dirigido-estratificado arqueológicamente) para el Valle del Tajuña madrileño -rentabilidad arqueológica-

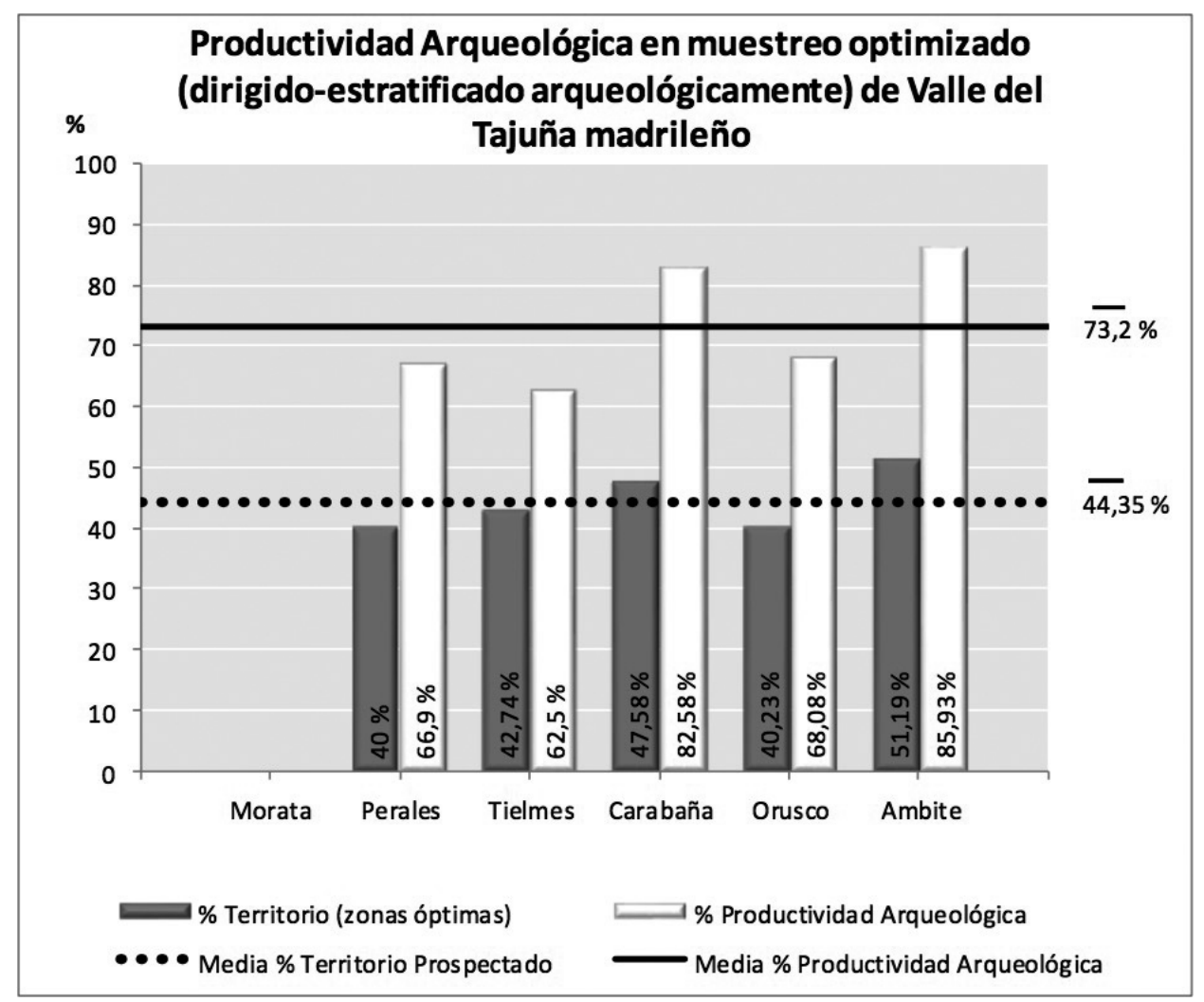

Fig. 8: Productividad arqueológica en muestreo optimizado (dirigido-estratificado arqueológicamente) para el Valle del Tajuña madrileño -rentabilidad arqueológica-. 
El proyecto de investigación del Valle del Tajuña madrileño ha supuesto el desarrollo de técnicas de prospección territorial previamente experimentadas en el Ecce Homo (Alcalá de Henares, Madrid) en los años 80 del siglo XX (Cristóbal Rodríguez 1986), pero sobre bases metodológicas más explicitas y objetivas. En conjunto, la prospección supuso 150 días de trabajo real, sin contar los perdidos por cualquier causa, en los que se dedicaron 581,70 horas a prospección y 400,50 a transportes, descanso, comida, etc. lo que supone una proporción de 1:0,68. Dicho tiempo supone un promedio de $1,34 \mathrm{~km} 2$ por día real de prospección y un coeficiente de $3,54 \mathrm{~h} / \mathrm{km} 2$. El número de componentes de los equipos de prospección varió según la época, zona a estudiar, etc., pero la media fue de 5,69 personas/día y $0,23 \mathrm{~km} 2$ diarios por persona ${ }^{7}$ (Fig. 20).
Particular interés se puso en estudiar primero y mejorar después la rentabilidad tanto en calidad como económica. Como calidad se ha considerado la precisión de los datos de prospección obtenidos. Para su contraste se ha recurrido a la comprobación aleatoria de zonas ya prospectadas cambiando el equipo y sin conocimiento previo de los sitios ya localizados, algo que trabajos más recientes valoran especialmente (Banning et al. 2017). El porcentaje de coincidencia, tanto de relocalización como de los no localizados en la prospección o en el control, es el índice de calidad de la prospección. A su vez, como rentabilidad se ha considerado la relación esfuerzo/rendimiento, que se puede medir en horas/sitio, horas/km2, $€ / \mathrm{km} 2$ o $€ /$ sitio. De este modo, los resultados alcanzados en la productividad, rentabilidad y coeficiente del Valle del Tajuña han sido muy interesantes (Figs. 9 y 10).

\begin{tabular}{|c|c|c|c|c|c|}
\hline \multicolumn{6}{|c|}{$\begin{array}{l}\text { PRODUCTIVIDAD/RENTABILIDAD/COEFICIENTE EN EL } \\
\text { VALLE DEL TAJUÑA MADRILEÑO }\end{array}$} \\
\hline Municipio & Sitios/hora & Sitios/km2 & Ptas.- $€$ / Sitio & Ptas. $-€ /$ km2 & Horas/km2 \\
\hline $\begin{array}{l}\text { Morata de Ta- } \\
\text { juña }\end{array}$ & 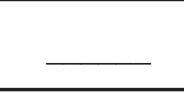 & 1,69 & $\begin{array}{c}17.241 \mathrm{ptas} \\
103,62 €\end{array}$ & $\begin{array}{c}22.124 \text { ptas. } \\
132,97 €\end{array}$ & \\
\hline $\begin{array}{l}\text { Perales de Ta- } \\
\text { juña }\end{array}$ & 0,55 & 3,06 & $\begin{array}{c}\text { 10791ptas. } \\
64,86 €\end{array}$ & $\begin{array}{l}\text { 30.675ptas. } \\
184,36 €\end{array}$ & 5,56 \\
\hline Tielmes & 0,76 & 3,60 & $\begin{array}{l}\text { 6.265ptas. } \\
37,65 €\end{array}$ & $\begin{array}{l}20.494 \text { ptas. } \\
123,17 €\end{array}$ & 4,74 \\
\hline Carabaña & 1,18 & 3,01 & $\begin{array}{l}\text { 7.390ptas. } \\
44,41 €\end{array}$ & $\begin{array}{c}20.494 p t a s \\
123,17 €\end{array}$ & 2,55 \\
\hline $\begin{array}{l}\text { Orusco de Ta- } \\
\text { juña }\end{array}$ & 1,11 & 2,62 & $\begin{array}{l}\text { 10.979ptas. } \\
\quad 65,99 €\end{array}$ & $\begin{array}{c}\text { 24.000ptas. } \\
144,24 €\end{array}$ & 2,35 \\
\hline Ambite & 1,08 & 2,72 & $\begin{array}{l}9.750 \text { ptas. } \\
58,60 €\end{array}$ & $\begin{array}{c}\text { 24.000ptas. } \\
144,24 €\end{array}$ & 2,51 \\
\hline$\overline{\mathrm{X}{\text { (media })^{8}}^{8}}$ & 0,94 & 2,78 & $\begin{array}{l}\overline{10.403 p t a s} \\
62,52 €\end{array}$ & $\begin{array}{c}\text { 23.631ptas. } \\
142,03 €\end{array}$ & 3,54 \\
\hline
\end{tabular}

Fig. $9^{8}$ : Productividad/rentabilidad/coeficiente en el Valle del Tajuña madrileño.

La productividad se obtiene a través de dos fórmulas: 1. Sitios/hora, que resulta de dividir los sitios arqueológicos localizados entre las horas reales de prospección; 2 . Sitios $/ \mathrm{km} 2$, que es consecuencia de dividir los sitios arqueológicos localizados entre los kilómetros cuadrados prospectados. En cuanto a la rentabilidad, ésta se consigue de dos maneras: 1 . Euros/Sitio, que se consigue de dividir el presupuesto (dinero) adjudicado por la administración al proyecto entre el número de sitios arqueológicos localizados; 2. Euros $/ \mathrm{km}^{2}$, que es fruto de la división del presupuesto (dinero) adjudicado por la administración al proyecto entre los kilómetros cuadrados del término municipal (territorio). El coeficiente se alcanza dividiendo las horas reales de prospección entre los kilómetros cuadrados inspeccionados. 
Así, se comprueba que a lo largo del trabajo realizado en el Proyecto Tajuña se ha ido incrementando la eficacia de la prospección, lo que evidencia el avance logrado desde el punto de vista metodológico y supone un progreso en la rentabilidad científica y económica que se puede comprobar en prospecciones futuras. En efecto, toda prospección arqueológica supone una inversión económica y en esfuerzo humano y de tiempo cuya rentabilidad se justifica por los resultados obtenidos, hecho muy tenido en cuenta en estos trabajos de investigación metodológica en los que se ha puesto particular atención en la mejora de la rentabilidad económica y arqueológica (Figs. 9 y 10).

En esta prospección se ha estudiado el $87,75 \%$ del territorio, lo que supone una identificación de sitios y una confianza casi del 90\%, pero el coste de tiempo y medios empleados según éste estudio puede considerarse excesivo en relación a los resultados. En efecto, un estudio analítico de los mismos ha precisado que es posible prospectar con un alto grado de confianza, superior al $80 \%$, zonas óptimas ${ }^{9}$ predeterminadas que suponen en torno al $40 \%$ $(44,35 \%)$ del territorio pero que contienen más del $70 \%$ de los sitios $(73,20 \%$ ) (Figs. 7 y 8 ), lo que disminuye el esfuerzo sin pérdida sensible en los resultados. Esto permite aumentar la eficacia y, algo que en ocasiones es más importante, la inversión en tiempo.

De esta manera, si se analiza el mapa de dispersión de sitios de los distintos municipios del Valle, comenzando por el término de Perales, se observa que las cuadrículas totalmente prospectadas evidencian cómo los hallazgos se concentran en una banda geográfica correspondiente a la Vega del Tajuña con sus laderas (filas M-L-K; $\mathrm{n}=10$ ) y al Arroyo de la Vega (columnas 5-6-7; $\mathrm{n}=16$ ) (Fig. $11-2-$ ) (Benito-López 2016: Fig. III.3). Las primeras suponen menos del $15 \%$ del territorio, pero contienen el $32 \%$ de los sitios y las segundas el $25 \%$ del territorio y el $35 \%$ de los sitos respectivamente (Almagro-Gorbea y Benito-López 1993b: fig. 2). En consecuencia, estas 26 cuadrículas suponen menos del $40 \%$ del territorio pero contienen el $66,90 \%$ del total de sitios localizados, incluyendo los dispersos y aislados del páramo, lo que pone más en evidencia esta concentración que se repite regularmente a lo largo del Valle y muestra la distribución de sitios arqueológicos por zonas geográficas que explica la existencia de las citadas zonas óptimas (Figs. 7, 8 y 12).

\begin{tabular}{|c|c|c|c|}
\hline \multicolumn{4}{|c|}{ RENTABILIDAD ARQUEOLÓGICA EN PERALES DE TAJUNA } \\
\hline $\begin{array}{c}\text { Unidades topográfi- } \\
\text { co-ecológicas }\end{array}$ & \% Unidad & $\begin{array}{c}\text { Rentabilidad \% sitios } \\
\text { arqueológicos }\end{array}$ & $\begin{array}{c}\text { Rentabilidad No sitios } \\
\text { arqueológicos }\end{array}$ \\
\hline Vega & 7,30 & 10,07 & 14 \\
\hline Ladera & 32,50 & 56,12 & 78 \\
\hline Páramo & 53,17 & 33,81 & 47 \\
\hline TOTAL & & & 139 \\
\hline
\end{tabular}

Fig. 12: Rentabilidad arqueológica en Perales de Tajuña. 

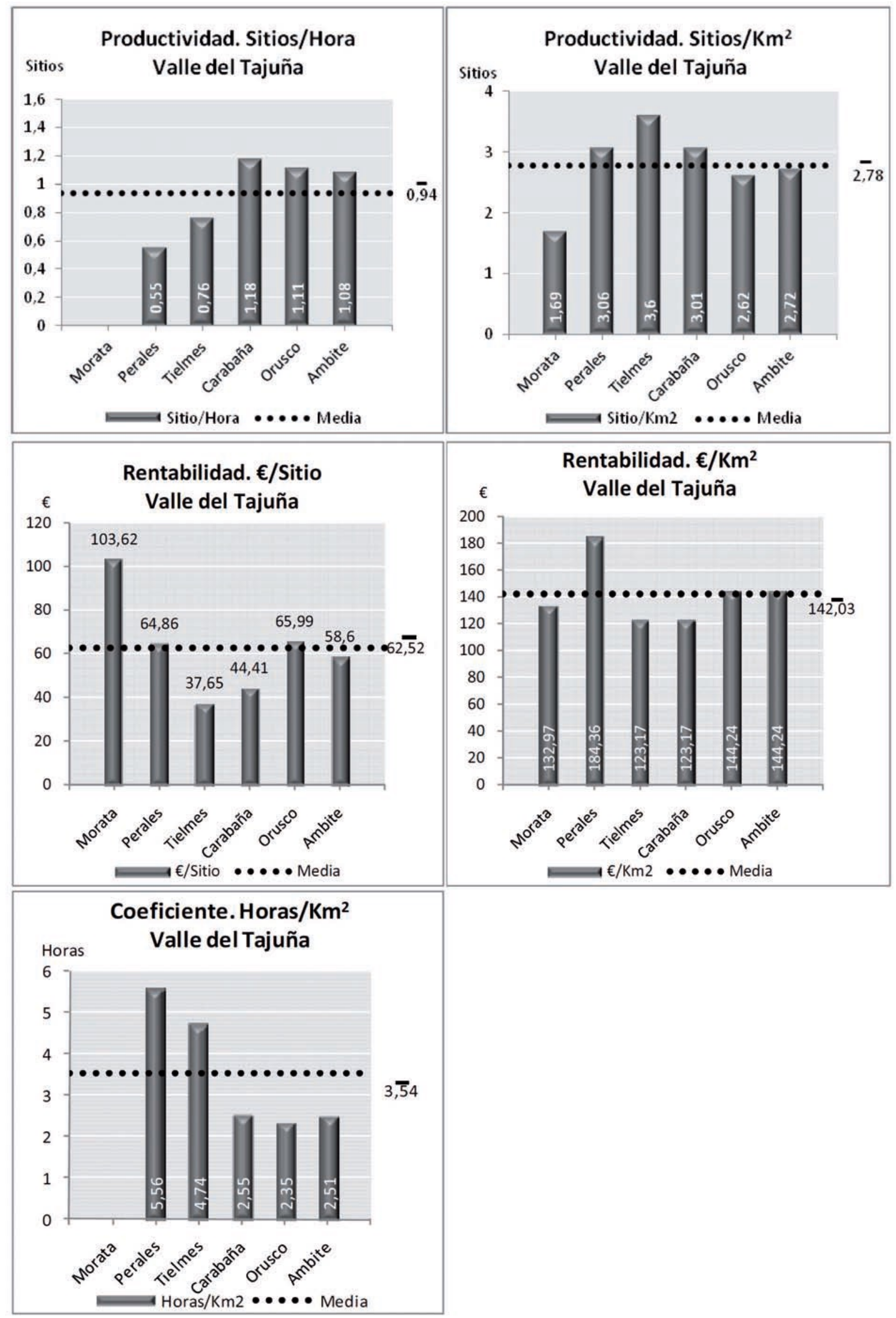

Fig. 10: Histogramas con los resultados de la productividad/rentabilidad/coeficiente del Valle del Tajuña madrileño. 

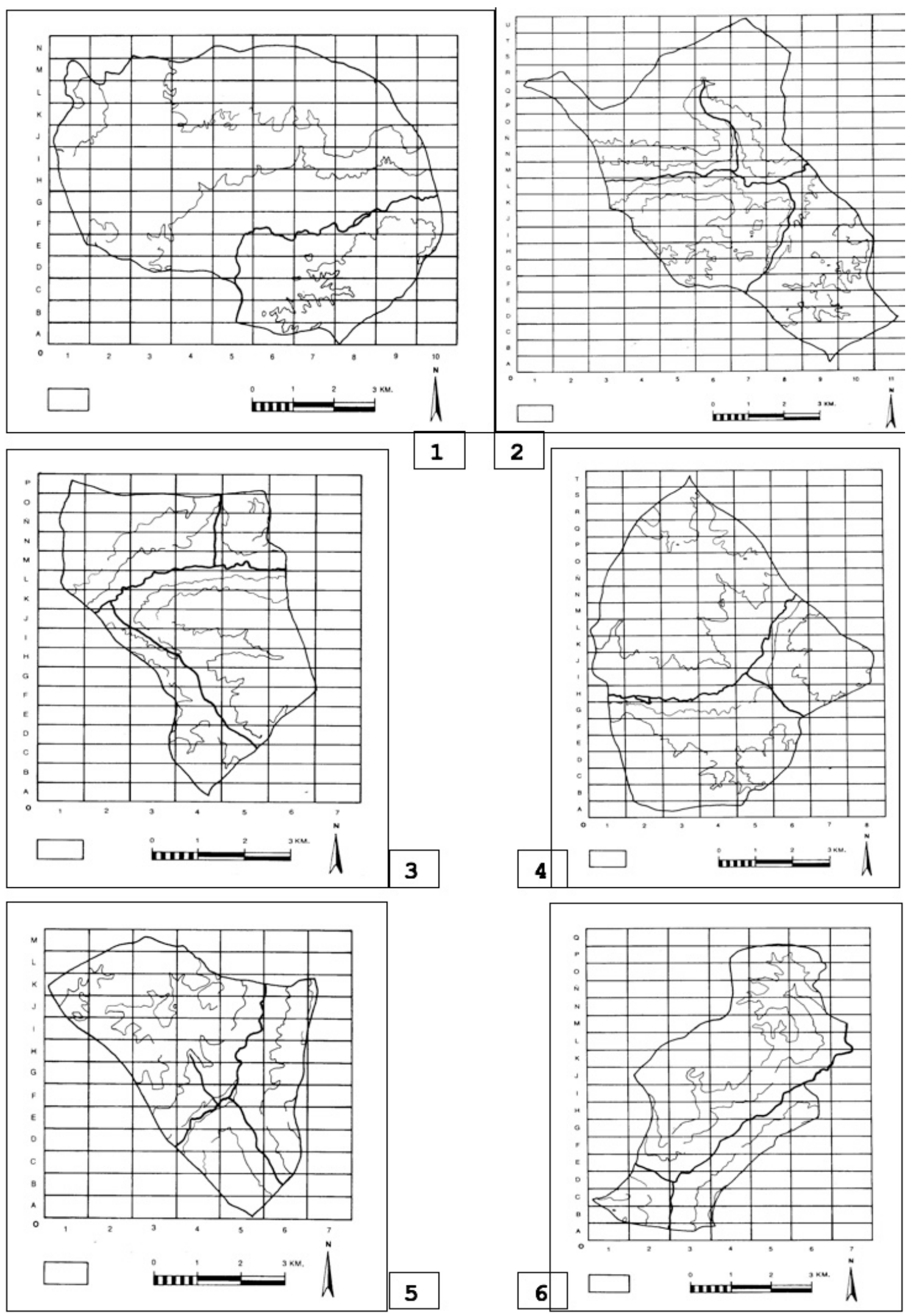

Fig. 11: Términos municipales del Valle del Tajuña (1. Morata, 2. Perales, 3. Tielmes, 4. Carabaña, 5. Orusco y 6. Ambite) divididos en unidades analíticas de prospección (transects-cuadrículas) de 0,5 x 1 $\mathrm{km}$, tomado del mapa topográfico 1:50.000. 
Continuando éste análisis de las zonas optimas, prospectadas primeramente, en otros términos del Valle del Tajuña, se comprueba que el territorio inspeccionado evidencia la concentración de los hallazgos arqueológicos en una banda geográfica (topográfico-ecológica) correspondiente a la vega del Tajuña con sus laderas y a los distintos arroyos -afluentes- de dicho río. De este modo, en Tielmes las cuadrículas totalmente prospectadas evidencian que los sitios arqueológicos se extienden en una franja geográfica correspondiente a la vega del río y sus laderas (filas L-M-N y columnas 2-3-4-5-6; $\mathrm{n}=14)$ y los arroyos de la Vega (filas $\mathrm{N}-\mathrm{O}$ y columna $4 ; \mathrm{n}=2$ ) y de Valdecañas (cuadrículas D5, E5, F4, G4, H4, I3, J3; n= 7) (Fig. 11 -3-) (Benito-López 2016: Fig. III.4). Las primeras suponen el 26,02\% del territorio pero contienen el $42,05 \%$ de los sitios; las segundas solamente el 3,71\% y $3,41 \%$ respectivamente, y las terceras el $13,01 \%$ del territorio pero con un $17,04 \%$ de sitios hallados. En consecuencia, éstas 23 cuadrículas suponen el $42,74 \%$ del territorio pero contienen el $62,50 \%$ del total de los sitios localizados (Figs. 7, 8 y 13).

\begin{tabular}{|c|c|c|c|}
\hline \multicolumn{4}{|c|}{ RENTABILIDAD ARQUEOLÓGICA EN TIELMES } \\
\hline $\begin{array}{c}\text { Unidades topográfi- } \\
\text { co-ecológicas }\end{array}$ & \% Unidad & $\begin{array}{c}\text { Rentabilidad \% sitios } \\
\text { arqueológicos }\end{array}$ & $\begin{array}{c}\text { Rentabilidad N } \text { sitios }^{\text {arqueológicos }} \\
\text { arque }\end{array}$ \\
\hline Vega & 16,69 & 18,18 & 16 \\
\hline Ladera & 32,05 & 54,55 & 48 \\
\hline Páramo & 42,19 & 27,27 & 24 \\
\hline TOTAL & & & 88 \\
\hline
\end{tabular}

Fig. 13: Rentabilidad arqueológica en Tielmes.

En Carabaña, se han prospectado las zonas optimas de la vega del río y el arroyo Valdemartín, además de ciertas zonas de páramo en busca de la posible vía romana Complutum-Segobriga-Cartago Nova (Fig. 11 -4-) (Benito-López 2016: Fig. III.5), habiéndose inspeccionado el $47,58 \%$ de la zona pero con un rendimiento del $82,58 \%$ de los yacimientos, incluyendo los dispersos y aislados del páramo, lo que pone más en evidencia esta concentración (Figs. 7, 8 y 14).

\begin{tabular}{|c|c|c|c|}
\hline \multicolumn{4}{|c|}{ RENTABILIDAD ARQUEOLÓGICA EN CARABAÑ } \\
\hline $\begin{array}{c}\text { Unidades topográfi- } \\
\text { co-ecológicas }\end{array}$ & \% Unidad & $\begin{array}{c}\text { Rentabilidad \% sitios } \\
\text { arqueológicos }\end{array}$ & $\begin{array}{c}\text { Rentabilidad No sitios } \\
\text { arqueológicos }\end{array}$ \\
\hline Vega & 9,58 & 20,46 & 27 \\
\hline Ladera & 32,02 & 64,39 & 85 \\
\hline Páramo & 50,50 & 15,15 & 20 \\
\hline & & & 132 \\
\hline TOTAL & 92,10 & 100,00 & \\
\hline
\end{tabular}

Fig. 14: Rentabilidad arqueológica en Carabaña.

En Orusco de Tajuña se han inspeccionado las zonas de la vega del río junto con sus laderas y el arroyo de Valdeormeña y sus laderas (Fig. 11 -5-) (Benito-López 2016:
Fig. III.6), dando unos resultados: 40,23\% de territorio prospectado y una rentabilidad del $68,08 \%$ de los sitios arqueológicos (Figs. 7 , 8 y 15$)$. 


\begin{tabular}{|c|c|c|c|}
\hline \multicolumn{4}{|c|}{ RENTABILIDAD ARQUEOLÓGICA EN ORUSCO DE TAJUÑ } \\
\hline $\begin{array}{c}\text { Unidades topográfi- } \\
\text { co-ecológicas }\end{array}$ & \% Unidad & $\begin{array}{c}\text { Rentabilidad \% sitios } \\
\text { arqueológicos }\end{array}$ & $\begin{array}{c}\text { Rentabilidad No sitios } \\
\text { arqueológicos }\end{array}$ \\
\hline Vega & 8,37 & 12,76 & 6 \\
\hline Ladera & 39,40 & 65,96 & 31 \\
\hline Páramo & 35,86 & 21,28 & 10 \\
\hline TOTAL & & & 47 \\
\hline
\end{tabular}

Fig. 15: Rentabilidad arqueológica en Orusco de Tajuña.

En Ambite la prospección se centró en la vega y laderas del río además del arroyo Vega y alguna extensión de páramo -como en Carabaña- (Fig. 11 -6-) (Benito-López 2016: Fig.
III.7). El resultado fue el 51,19\% del término prospectado, con una productividad del $85,93 \%$ de los hallazgos arqueológicos ${ }^{10}$ (Figs. 7, 8 у 16$)$.

\begin{tabular}{|c|c|c|c|}
\hline \multicolumn{4}{|c|}{ RENTABILIDAD ARQUEOLÓGICA EN AMBITE } \\
\hline $\begin{array}{c}\text { Unidades topográfi- } \\
\text { co-ecológicas }\end{array}$ & \% Unidad & $\begin{array}{c}\text { Rentabilidad \% sitios } \\
\text { arqueológicos }\end{array}$ & $\begin{array}{c}\text { Rentabilidad No sitios } \\
\text { arqueológicos }\end{array}$ \\
\hline Vega & 8,24 & 3,13 & 2 \\
\hline Ladera & 42,61 & 84,37 & 54 \\
\hline Páramo & 39,61 & 12,50 & 8 \\
\hline & & & 64 \\
\hline TOTAL & 90,46 & 100,00 & \\
\hline
\end{tabular}

Fig. 16: Rentabilidad arqueológica en Ambite.

Localizar el patrón de prospección del territorio a prospectar en las fases iniciales permite predeterminar las zonas óptimas de prospección y aumentar la eficacia y el ahorro de tiempo sin pérdida de fiabilidad. En consecuencia, se ha logrado predeterminar objetivamente este patrón de prospección que permiten un muestreo optimizado (dirigido-estratificado arqueológicamente) para identificar una alta proporción de sitios, en torno a un $70 \%-73,20 \%$-, con una confianza $>80 \%$, pero prospectando sólo extensiones reducidas, en torno al $40 \%-44,35 \%$-, lo que supone un alto ahorro de tiempo, medios y personal. La fiabilidad se puede aumentar fácilmente si se amplía hasta el $50 \%$ el territorio prospectado por este procedimiento (Figs. 5, 7 y 8). E sta mejora metodológica tiene su principal aplicación en casos de prospecciones territoriales de urgencia que afecten a amplias áreas así como en casos, relativamente frecuentes, en los que la limitación de medios aconseje este tipo de optimización de los recursos.
Por otra parte, si bien en el Valle del Tajuña madrileño no han aparecido yacimientos de importancia singular, el Proyecto Tajuña ha proporcionado una productividad arqueológica alta comparable a otros territorios de España (Ruiz Zapatero 1997: 22-24) e incluso de Europa, habiendo localizado 528 sitios arqueológicos (259 yacimientos y 269 hallazgos aislados). Estos datos han supuesto una proporción media de 2,78 sitios $/ \mathrm{km} 2$, de los que 1,36 yacimientos $/ \mathrm{km} 2$ y 1,42 hallazgos aislados/km2 (Fig. 17). Si los datos se analizan de forma individualizada por términos municipales se puede observar que la mayor densidad arqueológica se sitúa en la zona central del valle -Perales, Tielmes y Carabaña(Figs. 17, 18 y 19), descendiendo un poco en la parte septentrional del Tajuña (Orusco de Tajuña y Ambite) y siendo bastante más acusada en la zona más meridional (Morata de Tajuña). 


\begin{tabular}{|c|c|c|c|c|c|c|}
\hline Municipio & $\mathbf{N}^{0}$ Sitios & $\begin{array}{l}\mathrm{N}^{0} \text { Yaci- } \\
\text { mientos }\end{array}$ & $\begin{array}{l}\mathbf{N}^{0} \text { Hallaz- } \\
\text { gos aislados }\end{array}$ & Sitios / km2 & $\begin{array}{l}\text { Yacimientos } \\
\qquad / \mathbf{k m} 2\end{array}$ & $\begin{array}{c}\text { Hallazgos } \\
\text { aislado / } \\
\text { km2 }\end{array}$ \\
\hline $\begin{array}{l}\text { Morata de } \\
\text { Tajuña }\end{array}$ & 58 & 13 & 45 & 1,69 & 0,38 & 1,31 \\
\hline $\begin{array}{l}\text { Perales de } \\
\text { Tajuña }\end{array}$ & 139 & 68 & 71 & 3,06 & 1,50 & 1,56 \\
\hline Tielmes & 88 & 47 & 41 & 3,60 & 1,92 & 1,68 \\
\hline Carabaña & 132 & 81 & 51 & 3,01 & 1,85 & 1,16 \\
\hline $\begin{array}{l}\text { Orusco de } \\
\text { Tajuña }\end{array}$ & 47 & 21 & 26 & 2,62 & 1,17 & 1,45 \\
\hline Ambite & 64 & 29 & 35 & 2,72 & 1,23 & 1,49 \\
\hline$\frac{\text { TOTAL/ }}{}$ & 528 & 259 & 269 & 2,78 & 1,36 & $\overline{1,42}$ \\
\hline
\end{tabular}

Fig. 17: I. Productividad arqueológica del Valle del Tajuña madrileño.

Así, el motivo de la leve disminución de la productividad arqueológica en la zona más septentrional puede ser debido a causas culturales que suponen que los sitios arqueológicos se emplacen principalmente en el territorio con una posición estratégica más óptima. En el caso del Tajuña madrileño sería el área cen- tral del mismo ya que presenta características mejores del territorio para su control además de superiores comunicaciones -la vía Complutum - Segobriga - Cartago Nova cruza el municipio de Carabaña y otras vías secundaria recorren los términos municipales de Tielmes, Perales y Morata- (Figs. 17, 18 y 19).

\begin{tabular}{|c|c|c|c|c|}
\hline \multicolumn{5}{|c|}{ II. PRODUCTIVIDAD ARQUEOLÓGICA DEL VALLE DEL TAJUÑ MADRILEÑO } \\
\hline Municipio & Superficie km2 & Superficie \% & $\begin{array}{c}\mathbf{N}^{\mathbf{0}} \text { Sitios } \\
\text { arqueológicos }\end{array}$ & $\begin{array}{c}\text { \% Sitios } \\
\text { arqueológicos }\end{array}$ \\
\hline Morata de Tajuña & 45,2 & 20,91 & 58 & 10,98 \\
\hline Perales de Tajuña & 48,9 & 22,63 & 139 & 26,33 \\
\hline Tielmes & 26,9 & 12,45 & 88 & 16,67 \\
\hline Carabaña & 47,6 & 22,03 & 132 & 25,00 \\
\hline Orusco de Tajuña & 21,5 & 9,95 & 47 & 8,90 \\
\hline Ambite & 26,0 & 12,03 & 64 & 12,12 \\
\hline & & & & \\
\hline TOTAL & 216,1 & 100,00 & 528 & 100,00 \\
\hline
\end{tabular}

Fig. 18: II. Productividad arqueológica del Valle del Tajuña madrileño.

En cuanto a la disminución de la productividad arqueológica en el territorio más meridional (Morata de Tajuña) ésta se debe a causas metodológicas, puesto que el equipo de prospección fue impuesto por el INEM -Instituto Nacional de Empleo- y carecía de experiencia en este tipo de trabajos, a pesar de haber recibido unas prácticas previas. De este modo, aunque Morata presenta unas características territoriales óptimas como el caso de Perales, Tielmes y Carabaña los resultados arqueológicos no han sido los mismos ya que el método ha fallado, principalmente por ausencia del mismo (Figs. 17, 18 y 19). 


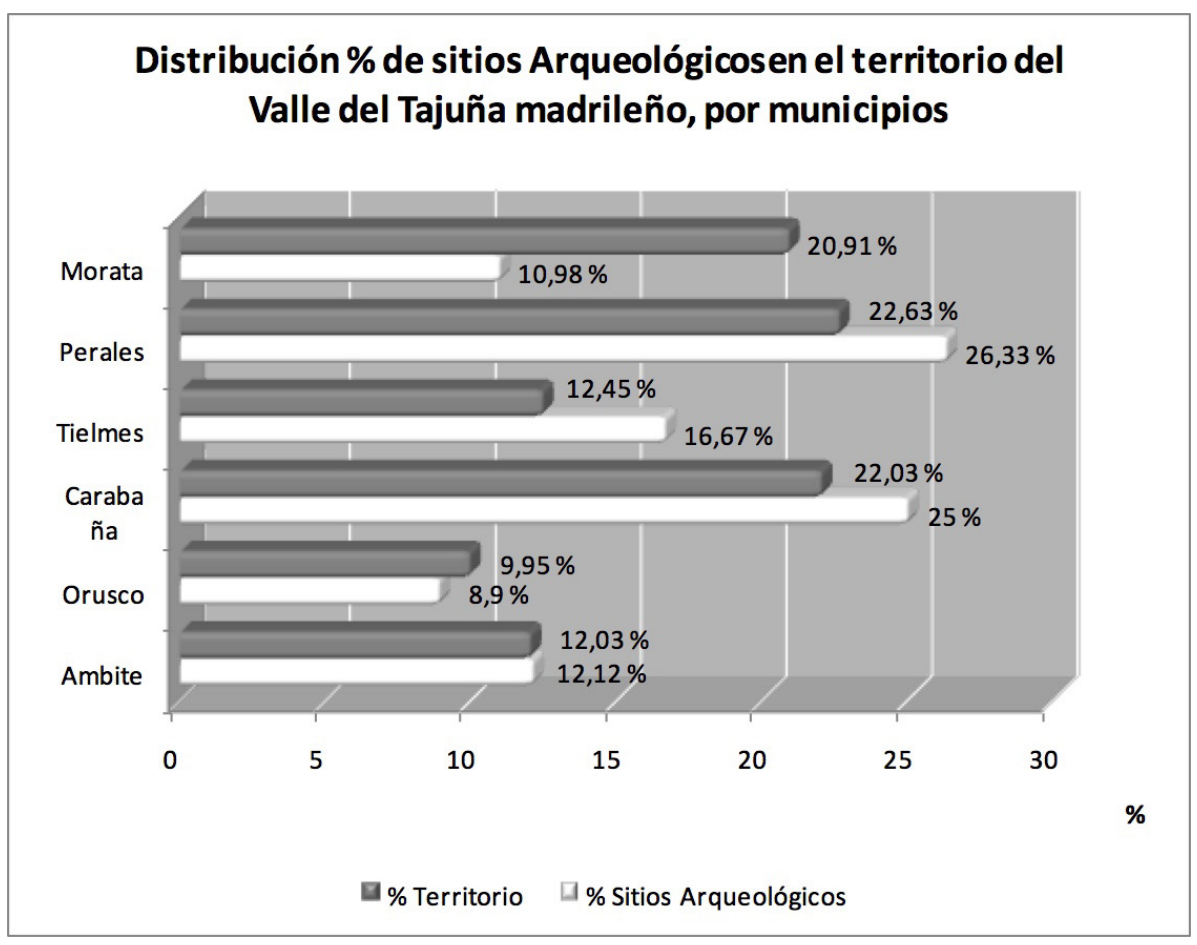

Fig. 19: Distribución porcentual de Sitios Arqueológicos en el Territorio del Valle del Tajuña Madrileño, por municipios.

Estos han sido los resultados de rentabilidad y productividad obtenidos en el Valle del Tajuña madrileño y su finalidad ha sido la de ayudar a aumentar la eficacia de la prospección, tanto desde el punto de vista metodológico como para su utilización científica y de gestión del Patrimonio Arqueológico y para la mejora de su rentabilidad económica. El reciente estudio de Banning et al. (2017: 467) destaca como únicas experiencias españolas los estudios del Tajuña (Almagro Gorbea et al. 1996 y 2002) como proyecto pionero a nivel internacional y muy próximo a los valores que defienden de Quality assurance. (QA). Entendida esta como el conjunto de medidas, procedimientos, orientaciones, estándares y sistemas que tiene por objetivo asegurar y mejorar la calidad de los productos, en este caso los resultados de los proyectos de prospección. Aunque, desgraciadamente para los arqueólogos, la mayoría de la literatura sobre $Q A$ se refiere a las industrias de manufacturación y servicios (Williams 1995).

\section{Conclusiones.}

Como recapitulación de lo presentado en este estudio destacan una serie de consideraciones a tener en cuenta en este tipo de proyectos y que expongo a continuación.

Los resultados logrados en esta investigación pueden considerarse de dos tipos, metodológico y arqueológico. La clave principal descansa en el establecimiento de un método teórico y su explicitación para la prospección de superficie -trabajo de campo- (Figs. 3 y 4). Ello puede ser de gran interés para la investigación arqueológica si se tiene en cuenta que, en la Península Ibérica, ha sido una característica relativamente usual de las prospecciones arqueológicas no detallar el método y las técnicas seguidas en los trabajos de campo, presentando directamente las conclusiones arqueológicas -reducidas primordialmente a los yacimientos arqueológicos y sus materiales-. No se podía evaluar la intensidad de las mismas puesto que faltaba la explicación del método. Ahora, con un método, su explicitación y los resultados arqueológicos, sí se puede medir la intensidad e incluso comparar con otras zonas (Alcock y Cherry 2004).

Un aspecto interesante en los resultados de la investigación ha sido el estudio del poblamiento de la zona en relación con su propio medio ecológico, ya que desde siempre las comunidades humanas han estado unidas 
al territorio lo que ocurre es que en mucho momentos se ha hecho caso omiso de esta conexión. En el trabajo se muestra la relación evidente (Fig. 2). Esta información completa el escaso conocimiento de la secuencia cultural de esta zona de la Meseta, precisando la falta de información de la muy deteriorada zona del Valle del Manzanares o del Henares aunque, evidentemente, esta parte del Valle del Tajuña ya puede asegurarse que ha sido casi siempre de menor importancia para el asentamiento humano. Simultáneamente, proporciona una primera secuencia cultural de la Meseta Sur, que puede ser contrastada en las referencias bibliográficas existentes (VV.AA. 1988; VV.AA. 2003; Pereira Sieso 2007; Madrigal y Perlines 2010; VV.AA. 2005-2014), aunque es evidente que exige trabajos complementarios desde las limitaciones inherentes al método.

\begin{tabular}{|c|c|c|c|c|c|c|c|}
\hline \multicolumn{8}{|c|}{ PARAMETROS DE PROSPECCIÓN EN EL VALLE DEL TAJUÑA MADRILEÑO } \\
\hline $\begin{array}{l}\text { Municipio } \\
\text { (superficie) } \\
\text { Km2 }\end{array}$ & $\begin{array}{l}\text { Morata de } \\
\text { Tajuna } \\
(45,2)\end{array}$ & $\begin{array}{l}\text { Perales de } \\
\text { Tajuna } \\
(48,9)\end{array}$ & $\begin{array}{l}\text { Tielmes } \\
(26,9)\end{array}$ & \begin{tabular}{|l|} 
Carabaña \\
$(47,6)$
\end{tabular} & $\begin{array}{l}\text { Orusco de } \\
\text { Tajuna } \\
(21,0)\end{array}$ & $\begin{array}{l}\text { A m b bite } \\
(26,0)\end{array}$ & $\begin{array}{l}\text { TOTAL/ } \\
(216,1) \\
\text { X (media) }\end{array}$ \\
\hline $\begin{array}{l}\text { Dias de } \\
\text { prospección }\end{array}$ & & 69 & 33 & 24 & 10 & 14 & 150 \\
\hline $\begin{array}{l}\mathrm{N}^{\circ} \text { de } \\
\text { prospectores }\end{array}$ & & 75 & 31 & 48 & 21 & 27 & 202 \\
\hline $\begin{array}{l}\mathrm{X} \text { (media) } \\
\text { personas/dia }\end{array}$ & & 5,56 & 5,39 & 6 & 6,10 & 5,42 & $\overline{5,69}$ \\
\hline $\begin{array}{l}\text { Horas } \\
\text { reales de } \\
\text { prospección }\end{array}$ & & 252,58 & 116,05 & 111,72 & 42,29 & 59,06 & 581,70 \\
\hline $\begin{array}{l}\mathrm{X} \text { (media) } \\
\text { diaria } \\
\text { prospección } \\
\text { real: horas }\end{array}$ & & 3,66 & 3,52 & 4,65 & 4,23 & 4,22 & $\overline{4,06}$ \\
\hline $\begin{array}{l}\text { Tiempo } \\
\text { logistico de } \\
\text { prospección } \\
\text { (horas) }\end{array}$ & & 172,50 & 88 & 68 & 30 & 42 & 400,50 \\
\hline $\begin{array}{l}\mathrm{X} \text { (media) } \\
\text { logistica } \\
\text { diaria (horas) }\end{array}$ & & 2,50 & 2,67 & 2,83 & 3 & 3 & $\overline{2,80}$ \\
\hline $\begin{array}{l}\text { Coeficiente: } \\
\text { hora/km2 }\end{array}$ & & 5,56 & 4,74 & 2,55 & 2,35 & 2,51 & $\overline{3,54}$ \\
\hline $\begin{array}{l}\text { Km2/día } \\
\text { prospectado }\end{array}$ & & 0,66 & 0,74 & 1,83 & 1,80 & 1,68 & $\overline{1,34}$ \\
\hline $\begin{array}{l}\text { Km2/dia } \\
\text { prospectado } \\
\text { por persona }\end{array}$ & & 0,12 & 0,14 & 0,30 & 0,30 & 0,31 & $\overline{0,23}$ \\
\hline $\begin{array}{l}\text { Superficie } \\
\text { prospectada } \\
\text { Km2 (\%) }\end{array}$ & & $\begin{array}{l}45,46 \\
(92,97)\end{array}$ & $\begin{array}{l}24,46 \\
(90,93)\end{array}$ & $\begin{array}{l}43,84 \\
(92,10)\end{array}$ & $\begin{array}{l}17,98 \\
(83,63)\end{array}$ & $\begin{array}{l}23,52 \\
(90,46)\end{array}$ & $\begin{array}{l}155,26 \\
(90,85)\end{array}$ \\
\hline
\end{tabular}

Fig. $20^{11}$ : Parámetros de prospección en el Valle del Tajuña madrileño. 
En lo que se refiere al Patrimonio Arqueológico, se puede ya avanzar la valoración de posibles áreas de particular interés que pudieran ser consideradas como zonas de protección arqueológica, entre las que destacan las Cuevas de Perales de Tajuña, ya declaradas Monumento Nacional en 1931, junto con algunos yacimientos situados sobre las terrazas del Tajuña a lo largo de todo el Valle (Fig. 2) (Benito-López 2016: 412-417, 704-706).

Igualmente ha sido positiva la labor de formación práctica en metodología de prospección desarrollada paralelamente con los estudiantes de la Universidad Complutense de Madrid (Benito-López 2016: 147-152), lo que ha supuesto una importante tarea de formación esencial para el futuro de este tipo de trabajos y para habituarles al control de resultados, que puede tener trascendencia positiva para el futuro (Benito-López 2016: 228-258). Por ello, se va comprobando la hipótesis de partida de que tanto desde el punto de vista científico -metodológico y arqueológico- como para la debida valoración cultural, resulta imprescindible un trabajo sistemático en áreas unitarias, como la que supone el Valle del Tajuña en su tramo madrileño.

Finalmente, en la prospección de este territorio hemos obtenido una serie de rasgos que, siguiendo la línea de la prospección arqueológica en España en estos últimos años (Ruiz Zapatero 1988, 1997 y 2004; García Sanjuán 2005; Burillo Mozota 2013), pueden ser positivos e incluso generalizables a otras prospecciones. Estas características son:

1. La utilización de un marco comarcal sobre unos criterios naturales -el Valle del Tajuña madrileño-. Este rasgo se puede extender a todas las prospecciones que sean realizadas en un futuro.

2. Trabajo en equipo. En el Valle del Tajuña madrileño osciló entre 3 y 9 componentes, con una media de 5,69 personas/día (Fig. 20). En general, el equipo debe estar en función de las necesidades de la propia prospección. Tal y como se ha comentado, el número de componentes variaba según la época o zona a inspeccionar, pero diariamente salía 1 o a lo sumo 2 personas con experiencia, en el grupo de inspección. De esta forma y aplicando nuestra propia práctica, llegamos a la consideración de que un grupo superior a 5 personas, con poca $\mathrm{o}$ nula experiencia, se hacía difícilmente con- trolable por una sola persona. Por el contrario, si el grupo era muy reducido, se hacía muy controlable pero la rentabilidad de la prospección pedestre en tiempo y consecuentemente económica no era la más idónea. Esto nos llevó a la conclusión de que en el Proyecto Tajuña, por sus características, un equipo de $4 / 5$ personas era ideal.

3. Ampliación de objetivos respecto a las antiguas prospecciones. En muestra prospección se ha incluido, junto a la evaluación y protección del Patrimonio Arqueológico (A.P.A.: Áreas de Protección Arqueológica) y el análisis cultural sincrónico-diacrónico dentro del medio, el estudio de los patrones de asentamiento en el Valle del Tajuña madrileño. Esta ampliación de objetivos puede ser generalizable a otras prospecciones y cada una puede adecuar los objetivos a su método de trabajo en el territorio.

4. Explicitación del diseño de la prospección y el desarrollo empírico de esta (Figs. $3 \mathrm{y}$ 4). Este es un rasgo general que hasta hace muy poco tiempo, todavía hoy día en muchos casos, estaba casi ausente en la arqueológica española (Benito-López 2016: 111-370). En esa tarea el control de la formación y experiencia de los prospectores, la opacidad de los restos arqueológicos en superficie -su variabilidad para ser detectados-, y la visibilidad de los distintos tipos de terreno constituyen temas cruciales (Banning et al. 2017: 473-474). Rigor que se debe ir imponiendo para que la prospección en España, alcance su propio estatus y pueda estar al nivel de las corrientes europeas (Bintliff 2014).

5. Controles temporales para tratar de rentabilizar la prospección. Se han tenido en cuenta una serie de factores importantes como el tiempo cronológico, visibilidad, intensidad de prospección, prospectores, experiencia, el medio, etc. (Benito-López 2016: 126-258) que han hecho posible hacer una serie de cálculos para el control y rentabilidad de la prospección. Este tipo de controles es necesario hacerlo en todas las prospecciones, debido a que hoy día son fundamentales dos aspectos como el tiempo y el dinero (Figs. 9 y 10). 
6. Controles de calidad: Los trabajos realizados sobre el Valle del Tajuña y sus zonas limítrofes han ofrecido un sistema para el control de calidad de los datos obtenidos en una prospección que representa una novedad en el marco internacional de la prospección. Es la prospección de control ya referida anteriormente. En esencia el método consiste en volver a prospectar una pequeña parte del territorio elegido -entre 0,2 y $8 \%$ del territorio total según su extensión- en lo que se denomina Prospección de Control, con unos requisitos mínimos. Este sistema de control de calidad de la prospección es poco costoso en tiempo y medios y permite conocer la fiabilidad de los resultados obtenidos en cualquier prospección arqueológica. Y, por supuesto, el conocimiento de la calidad de los resultados debe ser la última y definitiva etapa de los trabajos que supone toda prospección arqueológica (Almagro-Gorbea, Benito-López y Martín Bravo 1996: 251-264; Almagro-Gorbea et al. 2002: 45-53; Benito-López 2016: 241258).

7. Apoyo institucional del proyecto de prospección del Valle del Tajuña madrileño por parte de la Comunidad de Madrid (Consejería de Educación y Cultura). Es indudable que para conseguir este tipo de apoyos ha sido necesario hacer previamente unos planteamientos serios, sistemáticos y metodológicos dentro de unos marcos regionales y que sean tan atrayentes como las excavaciones, para que estos trabajos sean subvencionados en igual medida que estas.

8. Todos estos rasgos creemos que deben llevar y de hecho lo han conseguido, hacia una última e importante característica que es la creciente importancia de la prospección de superficie en estos últimos años.

En definitiva, este trabajo ha pretendido llamar la atención sobre la necesidad de analizar los datos obtenidos a través de la prospección arqueológica de superficie antes de proceder a su interpretación. Para ello hemos acudido a los datos conseguidos en una investigación realizada en un área de la Meseta Sur española
(Valle del Tajuña, Madrid) y a una serie de parámetros de análisis. Se trata, somos conscientes de ello, de una propuesta que ha centrado su atención en los factores controlables por el arqueólogo y a la que cabría sumar algún otro no cuantificado, algunos ya recogidos por estudios anteriores -perceptibilidad, visibilidad, la accesibilidad o algunos procesos postdeposicionales- (Burillo et al. 1981; Benito-López 1993: 75-94; VV.AA. 1993; García Sanjuán 2005, Burillo Mozota 2013). En cualquier caso, el objetivo principal del trabajo pretendía llamar la atención sobre la necesidad de dar un nuevo impulso en los estudios de Arqueología Territorial.

Su finalidad ha sido la de contribuir a incrementar la eficacia de la prospección arqueológica de superficie, tanto desde el punto de vista metodológico como para su utilización científica y de gestión del Patrimonio Arqueológico y para la mejora de su rentabilidad económica. Porque resulta evidente que la reputación y el profesionalismo en los proyectos de prospección dependen, por un lado, en asegurar que los vacíos de sitios son reales, pero también de la habilidad de caracterizar correctamente los materiales hallados, su densidad y su distribución. Garantizar la calidad de las prospecciones requiere buenos diseños y protocolos y la contrastación de prospectores y métodos de prospección para determinar su efectividad y empeñarse en su mejora (Banning et al. 2017: 485). Esa es la lección más importante del Proyecto Tajuña.

\section{Agradecimientos}

No habría podido realizar esta investigación sin los Profesores Martín Almagro Gorbea y Gonzalo Ruiz Zapatero (Departamento de Prehistoria de la Universidad Complutense de Madrid), maestros y verdaderos promotores de esta investigación, que siempre han velado por su desarrollo y de los que he aprendido el valor del trabajo, el esfuerzo, la constancia, la humildad, la honestidad y la honradez. Su guía, sus conocimientos y consejos han resultado fundamentales y mi agradecimiento es grande y sincero. De ambos he aprendido mucho... y sigo aprendiendo. Su sabiduría y consejos han mejorado notablemente el resultado final. 


\section{Bibliografía.}

Alcock, S. A. y Cherry, J. F. (eds.) (2004): Side-by-side survey. Comparative Regional Studies in the Mediterranean World. Oxford, Oxbow.

Almagro-Gorbea, M.; Alonso, P.; Benito-López, J. E.; Martín, A. M. y Valencia, J. L. (2002): Statistical Quality Control in Archaoelogical Survey. Archaeological Prospection, 9: 45-53.

Almagro-Gorbea, M. y Benito-López, J. E. (1993a): La prospección arqueológica del Valle del Tajuña. Una experiencia teórico-práctica de estudio territorial en la Meseta. Complutum, 4: 297-310.

— (1993b): Evaluación de rendimientos y optimización de resultados en prospección arqueológica: el Valle del Tajuña. En Jimeno martínez, A.; Val Recio, J. M. del y Fernández Moreno, J.J. (Eds.): Inventarios y Cartas Arqueológicas. Homenaje a D. Blas de Taracena (50 Aniversario de la primera Carta Arqueológica de España). 20-23 de Noviembre de 1991, Soria. Junta de Castilla y León, Valladolid: 151-158.

- y Martín Bravo, A. M. (1996): Control de calidad de resultados en prospección arqueológica. Complutum, 7: 251-264.

Banning, E. B. (2002): Archaeological Survey. Manual in Archaeological Method, Theory and Technique. Kluivert Academic Plenum Publishers. Nueva York.

—, Hawkins, A. L., Stewart, S. T., Hitchings, P., \& Edwards, S. (2017): Quality Assurance in Archaeological Survey, Journal of archaeological method and theory, 24(2): 466-488.

Benito-López, J. E. (1991): Perales de Tajuña (Madrid): un estudio de arqueología territorial. Teoría y práctica de la prospección arqueológica. Tesis de Licenciatura presentada el 26 de junio de 1991 en la Universidad Complutense. Texto inédito. Madrid.

- (1993): Análisis sistemáticos y procesos postdeposicionales en el valle del Tajuña (Madrid): un diseño de investigación y los resultados preliminares. Procesos Postdeposicionales. Arqueología Espacial, 16-17: 75-94.

- (2016): Estudio Territorial en el Valle del Tajuña (Madrid): una aproximación arqueológica. 2 Vols. Universidad Complutense. Madrid. 1126 pp.

Binford, L. R. (1964): A consideration of Archaeological Research Design. American Antiquity, 29: 425441.

Bintliff, J. L. (2014): Regional survey in the Mediterranean and Near East: A brief history and review of current approaches. En Regional Studies in Archaeology. Symposium Proceedings. Erciyas, D. B. y Sokmen, E. eds. Ankara, Middle East Technical University: 1-14.

Burillo Mozota, F. (2013): La prospección de superficie. En García-Díez, M. y Zapata, L. (eds.): Métodos y Técnicas de análisis y estudio en arqueología prehistórica. De lo técnico a la reconstrucción de los grupos humanos. Universidad del País Vasco: 15-38.

Burillo, F.; Gutiérrez, M. y Peña, J. L. (1981): El cerro del castillo de Alfambra (Teruel). Estudio interdisciplinar de Geomorfología y Arqueología. Revista Kalathos, 1: 7-63.

Burke, H., Morrison, M. y Smith, C. (2017): The Archaeologist's Field Handbook: The essential guide for beginners and professionals in Australia.(https:/www.researchgate.net/publication/312022130_The_Archaeologist's_Field_Handbook The essential guide for_beginners and professionals in_Australia).

Chapa Brunet, T.; Vicent, J. M.; Uriarte, A.; Mayoral, V. y Pereira, J. (2003): Propuesta metodológica para una prospección arqueológica sistemática: el caso del Guadiana Menor (Jaén, España). Trabajos de Prehistoria, 60, no 1: 11-34.

- (2004): Un programa de prospecciones arqueológicas para el Valle del Guadiana Menor (Jaén). Arqueología Espacial, 24-25: 123-144.

Clarke, D. L. (ed.) (1977): Spatial Archaeology. Academic Press. Londres.

Criado Boado, F.; López Sáez, J. A.; López Moreno, L.; Pérez Diaz, S. y Parcero Oubiña, C. (2009): Documentación y análisis palinológico de una posible terraza de cultivo en el castro de Follente (Caldas de Reis, Pontevedra). Trabajos de Prehistoria, vol. 66 (2): 171-182.

Criado Boado, F.; Ballesteros Arias, P. y Lima Oliveira, E. (2011): Use and division of land in Marco de Portovello (Lugo, NW Iberia). Archaeologia Medievale, no 38: 83-100.

Cristóbal Rodríguez, R. (1986): Estudio territorial en torno al Ecce Homo (Alcalá de Henáres, Madrid). Tesis de Licenciatura inédita presentada y defendida, en Septiembre de 1986, en la Universidad Complutense. Madrid.

Collins, J. M. y Molyneaux, B. L. (2003): Archaeological Survey. (Archaeologist's Toolkit, vol. 2). Lanham, MD, Altamira Press. 
- (2003): Archaeological Survey (Archaeologist's toolkit 2). Rowan Altamira / Altamira Press.

Connolly, D. (2015 [2008]): Field Survey, Field Walking and Detecting Survey. BAJR Practical Guide Series (Guide 15). (http://www.bajr.org/BAJRGuides/15.\%20Field\%20Survey\%20-\%20Land\%20Survey,\%20Fieldwalking\%20and\%20Metal\%20Detecting/ShortGuidetoFieldSurvey.pdf).

Dysson, S. L. (1982): Archaeological Survey in the Mediterranean Basin: A Review of Recent Research, American Antiquity, 47 (1): 87- 102.

Domínguez Macarro, A. y García Fernández, F. J. (2007): La prospección arqueológica en el suroeste peninsular: algunos problemas metodológicos. Caesaraugusta, $\mathrm{n}^{\circ}$ 78: 793-802.

Diez Martín, F. (2009): La arqueología de los espacios arados. Algunas puntualizaciones. Boletín del Seminario de Estudios de Arte y Arqueología, LXXV: 23-40.

- (2010): El arado y los yacimientos paleolíticos. Una década de investigación sobre el efecto del laboreo en los páramos del Duero. Complutum, 21 (1): 45-68.

García Sánchez, J. (2013): Metodologías de prospección a escala regional y artefactual. La prospección del Ager Segisamonensis; comarca Odra-Pisuerga (Burgos). Complutum, Vol. 24 (1): 9-28.

García Sanjuán, L. (2005): Introducción al Reconocimiento y Análisis Arqueológico del Territorio. Ariel Prehistoria. Barcelona.

—; Wheatley, D. y Costa Caramé, M. E. (2011): Prospección de superficie en Antequera, Málaga. 2006. Anuario Arqueológico de Andalucía 2006. Junta de Andalucía, Sevilla: 3716-3737.

Gerrad, Ch. M. y Gutiérrez, A. (2012): Estudio arqueológico del Somontano del Moncayo: avance metodológico. Salduie: Estudios de prehistoria y arqueología, $\mathrm{n}^{\circ}$ 10: 259-270.

Gutierrez, L. M.; Bellón, J. P. y Cebrián del Castillo, B. (2007): La Veguilla (Úbeda, Jaén). Prospección de superficie y caracterización del registro arqueológico. Caesaraugusta, 78: 781-792.

Hagget, P. (1976): Análisis Locacional en la Geografia Humana. Gustavo Gili. Barcelona. (1 a edición inglesa 1965).

Hodder, I. y Orton, C. (1976): Spatial analysis in Archaeology. Cambridge University Press. Cambridge. (Traducción española, Crítica, 1990).

Haselgrove, C.; Millet, M. y Smith, I. (eds.) (1985): Archaeology from the ploughsoil: Studies in the collection and interpretation of field survey data. Sheffield University Press. Sheffield.

Ifa (Institute for Field Archaeologists) (2008): Standard and guidance for the collection, documentation, conservation and research of archaeological materials. SHES. University of Reading.

Jimeno Martínez, A., Val Recio, J. M. del y Fernández Moreno, J. J. (Eds.) (1993): Inventarios y Cartas Arqueológicas. Homenaje a D. Blas de Taracena (50 Aniversario de la primera Carta Arqueológica de España). 20-23 de Noviembre de 1991, Soria. Junta de Castilla y León, Valladolid.

Keller, D. R. y Rupp, D. W. (eds.) (1983): Archaeological survey in the Mediterranean Area. British Archaeological Reports, International Series 155. Oxford.

King, Th. F. (1978): The Archaeological Survey: Methods and Uses. Washington, Heritage Conservation and Recreation Service, U.S. Department of the Interior.

Madrigal, A. y Perlines, M. (coords.) (2010): Actas de las II Jornadas de Arqueología de Castilla-La Mancha. 2 Vols. Marzo de 2007, Toledo. Albacete.

Mayoral Herrera, V. (ed.) (2016): La revalorización de zonas arqueológicas mediante el empleo de técnicas no destructivas: reunión científica. 12-13 de junio de 2014, Mérida (Badajoz, España). Anejos de Archivo Español de Arqueología, 75.

Mayoral Herrera, V.; Cerrillo Cuenca, E. y Celestino Pérez, S. (2009): Métodos de prospección intensiva en el marco de un proyecto regional: el caso de la comarca de La Serena (Badajoz). Trabajos de Prehistoria $66, n^{\circ} 1: 7-25$.

Mayoral Herrera, V., Parcero, C y Fábrega, P (eds.) (2017): Archaeology and geomatics. Harvesting the Benefits of 10 years of training in the Iberian Peninsula (2006-2015). Leiden: Sidestone Press.

Miller, C. L. (1989): Evaluating the effectiveness of archaeological survey. Ontario Archaeologist, 49: 3-12.

Moreno Escobar, $\mathrm{M}^{\mathrm{a}}$ C. (2011): Romanización, paisaje y territorio en las tierras de Antequera (Málaga, España): estudio del cambio cultural a través del análisis arqueológico espacial. Rómula, $\mathrm{n}^{\circ}$ 10: 46-39.

- (2016): Patrones de asentamiento en la Bética romana: un estudio del proceso de romanización desde el análisis arqueológico espacial. Tesis Doctoral. Universidad Pablo de Olavide. Sevilla.

— y García Sanjuán, L. (2013): Sistematización e informatización del inventario de yacimientos arqueológicos de Tierras de Antequera: la base de datos ARCA. Menga: Revista de Prehistoria de Anadalucia, $\mathrm{n}^{\circ}$ 4: 217-234. 
Orejas Saco del Valle, A. (2006): Arqueología de los paisajes agrarios e historia rural. Arqueología Espacial: Espacios Agrarios, 26: 7-19.

Pereira Sieso, J. (coord.) (2007): Prehistoria y Protohistoria de la Meseta Sur (Castilla-La Mancha). Ciudad Real.

Ruiz Zapatero, G. (1997): La Prospección de Superficie en la Arqueología española. La Prospección Arqueológica. Actas II Encuentros de Arqueología y Patrimonio. Salobreña (Granada) -15/17 Octubre 1991-: 13-34.

- (2004): La prospección arqueológica de superficie en los inicios del siglo XXI. Arqueología Espacial, 24-25: 17-32.

- y Burillo Mozota, F. (1988): Metodología para la investigación en arqueología territorial. Revista Munibe, Suplemento $\mathrm{n}^{\circ} 6$ (III Congreso Mundial Vasco, Vitoria): 45-64.

San Miguel Mate, L. C. (1992): El planteamiento y el análisis del desarrollo de la prospección: dos capítulos olvidados en los trabajos de Arqueología Territorial. Trabajos de Prehistoria, 49: 35-49.

Schofield, A. J. (ed.) (1991): Interpreting Artefact Scatters: contributions to ploughzone archaeology. Oxbow Monograph, 4. Oxbow Books. Oxford.

Taracena, B. (1926): Excavaciones en diversos lugares de la Provincia de Soria. Junta Superior de Excavaciones y Antigüedades. Madrid.

- (1941): Carta Arqueológica de España. Soria. C.S.I.C. Madrid.

Velasco Steigrad, F. (1991): El programa de Carta Arqueológica en la Comunidad de Madrid. Arqueología, Paleontología y Etnografia, 1: 257-280.

Vita-Finzi, C. (1969): The Mediterranean Valleys. Geological changes in historical times. Cambridge at the University Press. Cambridge.

VV. AA. (1988): I Congreso de Historia de Castilla-La Mancha. Ciudad Real, 1985.

- (1993): Procesos Postdeposicionales. Arqueología Espacial. Vols. 16-17. Teruel.

- (1997): La Prospección Arqueológica. Actas II Encuentros de Arqueología y Patrimonio. Salobreña (Granada) -15/17 de Octubre de 1991-.

- (2003): Investigaciones arqueológicas en Castilla-La Mancha, 1996-2002. Junta de Comunidades de Castilla-La Mancha. Toledo.

- (2004): Arqueología Espacial: Prospección. Vols. 24-25. Teruel.

- (2005-2014): Actas de las Jornadas de Patrimonio Arqueológico en la Comunidad de Madrid, $1^{a}-10^{a}$. Dirección General de Patrimonio Histórico / Museo Arqueológico Regional de la Comunidad de Madrid.

White, G. y King, Th. F. (2007): The Archaeological Survey Manual. Walnut Creek, CA., Left Coast Press. Williams, H. T. (1995): Quality assurance. A framework to build on. Oxford, Blackwell Science.

\section{Notas}

1. Bajo la dirección del Profesor Dr. D. Martín Almagro Gorbea y del Dr. D. José Enrique Benito López.

2. A quien agradecemos, con su Directora a la cabeza, todo su apoyo para poder llevar a feliz término el presente proyecto.

3. La forma de conseguir el obligatorio control de calidad de los resultados sobre una base científica es evaluando los sitios encontrados y siempre explicitando el método, la intensidad $(\mathrm{h} / \mathrm{km} 2)$ y el rendimiento $(€ / \mathrm{km} 2)$ obtenidos, así como los controles de los resultados y, también, ir mejorando el método hacia el futuro.

4. De todos modos, debe tenerse presente el valor relativo de estas conclusiones, dado que están basadas exclusivamente en prospección de superficie sin excavaciones que permitan obtener materiales arqueológicos y análisis para confirmar los resultados.

5. Siendo entendida como el número de yacimientos por unidad de superficie (Ruiz Zapatero y Burillo Mozota 1988: 50).

6. El 9,15\% restante hasta llegar al $100 \%$ se corresponden con zonas sin prospectar por corresponderse con áreas de: zona militar, vertederos, canteras, urbanizaciones, pinares, etc. Esta característica se produce, en mayor o menor medida, en todos los municipios del Valle del Tajuña.

7. En los resultados metodológicos del Valle del Tajuña, en lo que respecta al municipio de Morata no fue analizado ningún parámetro metodológico exceptuando la productividad arqueológica y la extensión 
prospectada. Este municipio fue inspeccionado por un equipo diferente al nuestro. De esta manera, de Morata solamente podremos utilizar los resultados arqueológicos, dejando al margen este término en los aspectos de método, debido a la falta de parámetros explícitos de prospección arqueológica.

8. La productividad arqueológica media asciende hasta 3 sitios arqueológicos por $\mathrm{km} 2$ si no se tiene en cuenta Morata de Tajuña. En cuanto a ptas.- $€ /$ sitio arqueológico, sin Morata, baja hasta 9.191ptas.$55,24 € /$ sitio con lo que se observa una mayor rentabilidad. En cuanto al aspecto ptas.- $€ / \mathrm{km} 2$, sin Morata, es 24.597 ptas.-147,83€, siendo muy similar a la media general.

9. Este método de prospección, muestreo optimizado (dirigido-estratificado arqueológicamente) (Almagro-Gorbea y Benito-López 1993a y 1993b) no fue experimentado en Morata de Tajuña, primer término municipal de ésta prospección.

10. En Orusco de Tajuña y Ambite, la llanura de inundación de la vega del Tajuña y sus afluentes se prospectó en un momento posterior al primer periodo de inspección, por ser el momento más adecuado para su rastreo.

11. Puntualizar que Morata de Tajuña fue prospectado por otro equipo diferente al del Proyecto Tajuña, no utilizando una metodología tan específica como la nuestra ni recogiendo datos tan precisos como los recogidos por el Proyecto Tajuña. Así, en el municipio de Morata los únicos parámetros identificados fueron la productividad arqueológica y la superficie prospectada. De este modo, la superficie prospectada en Morata fue de $34,37 \mathrm{kms} 2(76,04 \%)$ y si se suma al resto de los municipios del Valle del Tajuña se obtiene un total de $189,63 \mathrm{kms} 2(87,75 \%)$.

Datos de la tabla a considerar:* Días de Prospección = Días reales de prospección empleados en cada municipio. ${ }^{*} \mathrm{~N}^{\mathrm{o}}$ de prospectores $=$ número de personas que han participado en la prospección de cada término municipal. *Personas/días (Media): la media diaria de personas que han participado en la prospección de cada municipio. * Horas reales de prospección $=$ horas reales empleadas en la prospección de cada término municipal. $* \mathrm{X}$ diaria de prospección (horas) $=$ media diaria de prospección real contabilizada en horas. * Tiempo logístico de prospección (h.) = tiempo logístico dedicado a la prospección de cada municipio y medido en horas. Hemos considerado tiempo logístico todo aquel que no estaba dedicado a la inspección del territorio (prospección propiamente dicha), como puede ser transporte, paradas de descanso, comidas, etc. ${ }^{*} \mathrm{X}$ logística diaria $(\mathrm{h})=$ la media diaria dedicada a logística, en cada término municipal, medida en horas. * Coeficiente $(\mathrm{h} / \mathrm{km} 2)=$ en el caso del Valle del Tajuña resulta de dividir las horas empleadas en la prospección de cada municipio entre la extensión del mismo, dando como consecuencia el tiempo que se necesita (en horas) para prospectar un kilómetro cuadrado. ${ }^{*} \mathrm{Km} 2$ /día prospectados = kilómetros cuadrados prospectados diariamente en cada término municipal del Valle del Tajuña. * Km2/día prospectado/persona $=$ kilómetros cuadrados propectados diariamente por cada prospector. $*$ Es importante tener en cuenta que en la prospección del Valle del Tajuña el tiempo ha sido medido en horas centesimales. 